\title{
Urban Water Systems
}

"Today, a simple turn of the tap provides clean water-a precious resource. Engineering advances in managing this resource-with water treatment, supply, and distribution systemschanged urban life profoundly in the 20th century, virtually eliminating waterborne diseases in developed nations, and providing clean and abundant water for communities, farms, and industries." So states the US National Academy of Engineering on its selection of water supply systems to be among the top five greatest achievements of engineering in the twentieth century. But providing everyone with clean tap water, especially in urban areas, has yet to be achieved, even in developed nations. The world's population is growing by about 80 million people per year, and is predicted to approach 10 billion by 2050 . Over $50 \%$ of people on our planet today live in urban areas and that percentage will grow. As populations continually move to cities for improved economic opportunities and a higher standard of living and as cities merge to form megacities, the design and management of water becomes an increasingly important part of integrated urban infrastructure planning and management.

\subsection{Introduction}

Urban water management involves the planning, design, and operation of infrastructure needed to meet the demands for drinking water and sanitation, the control of infiltration and stormwater runoff, and for recreational parks and the maintenance of urban ecosystems. As urban areas grow, so do the demands for such services. In addition there is an increasing need to make urban water systems more resilient to climate change. All this leads to the realization that urban water management must be an integral part of urban planning in general. Land use decisions impact water supply and wastewater system designs and operation, as well as measures needed for managing stormwater runoff. A functioning urban infrastructure system also requires energy which in turn typically requires water.

Sustainable urban development must focus on the relationships between water, energy, and land use, and often on diversifying sources of water to assure reliable supplies. Integrated urban water management (IUWM) provides both a goal and a framework for planning, designing, and managing urban water systems. It is a flexible process that responds to change and enables stakeholders to participate in, and predict the impacts of, development decisions. It includes the environmental, economic, social, technical, and political aspects of urban water management. It enables better land use planning and the management of its impacts on fresh water supplies, treatment, and distribution; wastewater collection, treatment, reuse and disposal; stormwater collection, use and disposal; and solid waste collection, recycling, and disposal systems. It makes urban development part of integrated basin management oriented toward a more economically, socially, and environmentally sustainable mixed urban-rural landscape. 


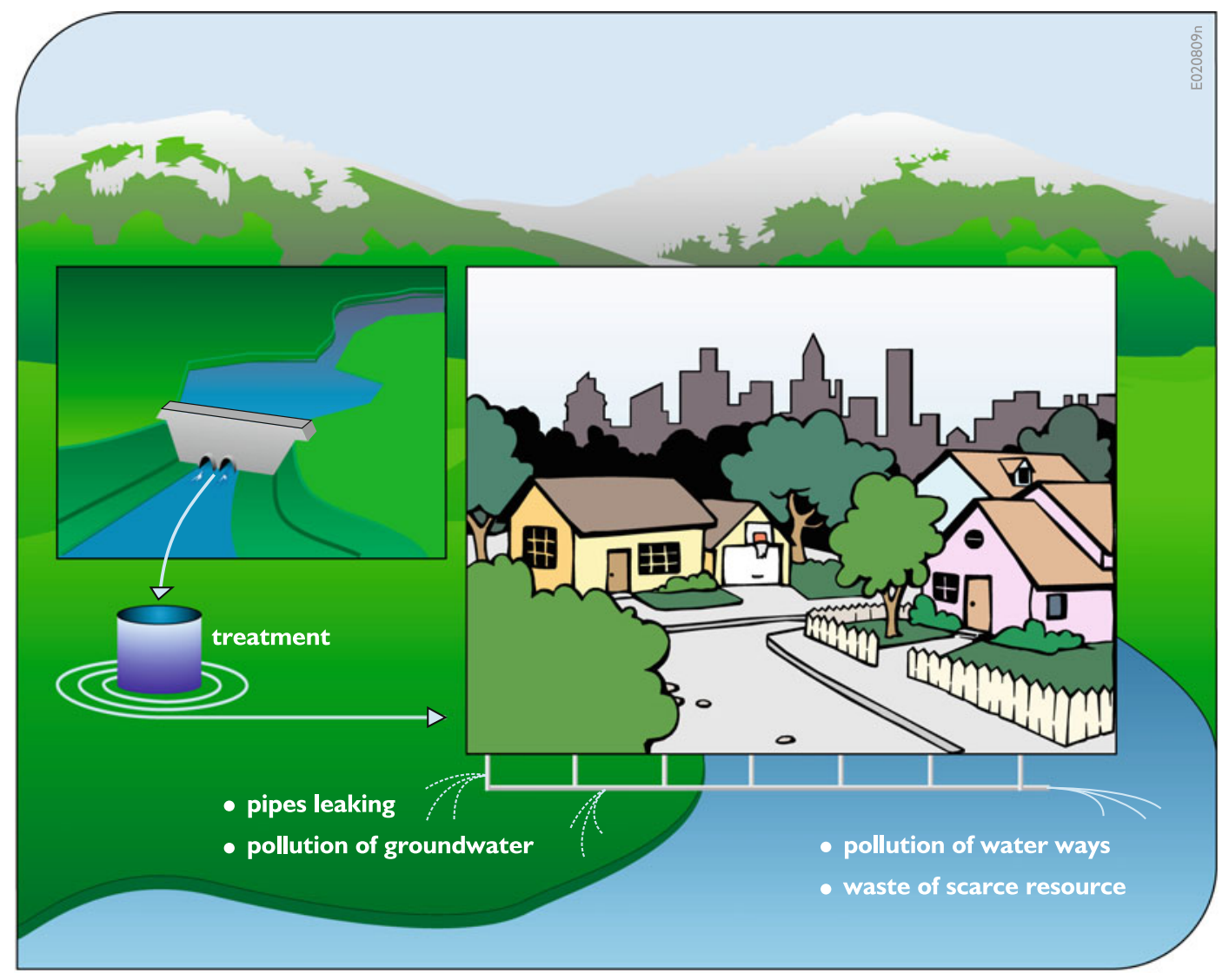

Fig. 12.1 Schematic showing urban surface water source, water treatment prior to urban use, and some sources of nonpoint urban drainage and runoff and its impacts

While recognizing the need for and the benefits derived from a systems approach to urban planning and development, including its water related components, this chapter will serve as an introduction to each of these components separately, and not all together as a system. This understanding of each component is needed if indeed they eventually will be modeled, designed, and managed as part of the overall urban infrastructure system.

These urban water infrastructure components typically include water collection and storage facilities at source sites, water transport via aqueducts (canals, tunnels, and/or pipelines) from source sites to water treatment facilities; water treatment, storage, and distribution systems; wastewater collection (sewer) systems and treatment; and urban drainage works. This is illustrated as a simple schematic in Fig. 12.1.

Generic data-driven simulation models of components of urban water systems have been developed and are commonly applied to study specific component design and operation issues. Increasingly optimization models are being used to estimate cost-effective designs and operating policies. Cost savings can be substantial, especially when applied to large complex urban systems (Dandy and Engelhardt 2001; Savic and Walters 1997).

Most urban water users desire, and many require, high quality potable water. The quality of natural surface and/or groundwater supplies, called raw water, often cannot meet the quality requirements of domestic and industrial users. In 
such situations water treatment prior to its use is required. Once treated, water can be stored and distributed within the urban area, usually through a network of storage tanks and pipes. Pipe flows in urban distribution systems should be under pressure to prevent contamination from groundwater leakage and to meet fire protection and other user requirements.

After use, the "wastewater" is collected in a network of sewers, or in some cases ditches, leading to a wastewater treatment plant or discharge site. Wastewater treatment plants remove some of the impurities in the wastewater before discharging it into receiving water bodies or on land surfaces. Water bodies receiving effluents from point sources such as wastewater treatment plants may also receive runoff from the surrounding watershed area during storm events. The discharge of point and nonpoint pollutants into receiving water bodies can impact the quality of the water in those receiving water bodies. The fate and transport of these pollutants in water bodies can be predicted using water quality models similar to those discussed in Chap. 10.

This chapter briefly describes these urban water system components and reviews some of the general assumptions incorporated into optimization and simulation models used to plan and manage urban water infrastructure systems. The focus of urban water systems modeling is mainly on the prediction and management of quantity and quality of flows and pressure heads in water distribution networks, wastewater flows in gravity sewer networks, and on the design efficiencies of water and wastewater treatment plants. Other models can be used for the real-time operation of various components of urban systems.

\section{Box 12.1 An urban drinking water crisis}

This ongoing (2016) case of urban water management in Flint, Michigan (US) illustrates what can happen even in so-called developed regions if decisions are made without adequate analyses of possible health impacts and the consequences of poor follow-up decisions at various governmental levels.

After a change in April 2014 of the source of the city's drinking water, the city's water distribution system became contaminated with lead. This has created a serious public health danger. As a result, thousands of residents have severely high levels of lead in their blood and are experiencing a variety of serious health problems. Local, state, and federal authorities, and political leaders, did not seem sufficiently concerned until inhabitants of Flint, with the help of others who performed water quality analyses and obtained public health statistics from local hospitals, made it a national issue. In November, 2015, some of the residents filed a federal class action lawsuit against the Governor and 13 other city and state officials. Additional lawsuits have been filed after that and resignations have occurred. In January 2016, the Governor declared the city to be in a state of emergency. Less than 2 weeks later the President of the US declared the drinking water crisis in Flint as a federal emergency authorizing additional help from the federal government.

\subsection{Water Treatment}

Before water is to be used for human consumption its harmful impurities need to be removed. Communities that do not have adequate water treatment facilities, common in developing regions, often have high incidences of disease and mortality due to contaminated water supplies. A range of syndromes, including acute dehydrating diarrhea (cholera), prolonged febrile illness with abdominal symptoms (typhoid fever), acute bloody diarrhea (dysentery), and chronic diarrhea (Brainerd diarrhea) result in over 3 billion episodes of diarrhea and an estimated 2 million deaths, mostly among children, each year.

Contaminants in natural water supplies can include microorganisms such as Cryptosporidium 
and Giardia lamblia, inorganic and organic cancer-causing chemicals (such as compounds containing arsenic, chromium, copper, lead, and mercury), and radioactive materials (such as radium and uranium). As Box 12.1 illustrates, this need to protect water supplies from such contaminants is not limited to developing regions.

To remove impurities and pathogens, a typical municipal water purification system involves a sequence of physical and chemical processes. Physical and chemical removal processes include initial and final filtering, coagulation, flocculation sedimentation, and disinfection, as illustrated in the schematic of Fig. 12.2.

As shown in Fig. 12.2, one of the first steps in most water treatment plants involves passing raw water through coarse filters to remove sand, grit, and large solid objects. Next, a chemical such as alum is added to the raw water to facilitate coagulation of remaining impurities. As the wastewater is stirred the alum causes the formation of sticky globs of small particles made up of bacteria, silt, and other impurities. Once these globs of matter are formed, the water is routed to a series of settling tanks where the globs, or floc, sink to the bottom. This settling process is called flocculation.
After flocculation the water is pumped slowly across another large settling basin. In this sedimentation or clarification process much of the remaining floc and solid material accumulates at the bottom of the basin. The clarified water is then passed through layers of sand, coal, and other granular material to remove microorganisms - including viruses, bacteria, and protozoa such as Cryptosporidium-and any remaining floc and silt. This stage of purification mimics the natural filtration of water as it moves through the ground.

The filtered water is then treated with chemical disinfectants to kill any organisms that remain after the filtration process. An effective disinfectant is chlorine but its use may cause potentially dangerous substances such as trihalomethanes.

Alternatives to chlorine include ozone oxidation (Fig. 12.2). Unlike chlorine, ozone does not stay in the water after it leaves the treatment plant, so it offers no protection from bacteria that might be in the storage tanks and water pipes of the water distribution system. Water can also be treated with ultraviolet light to kill microorganisms, but it has the same limitation as oxidation. It is ineffective outside the treatment plant.

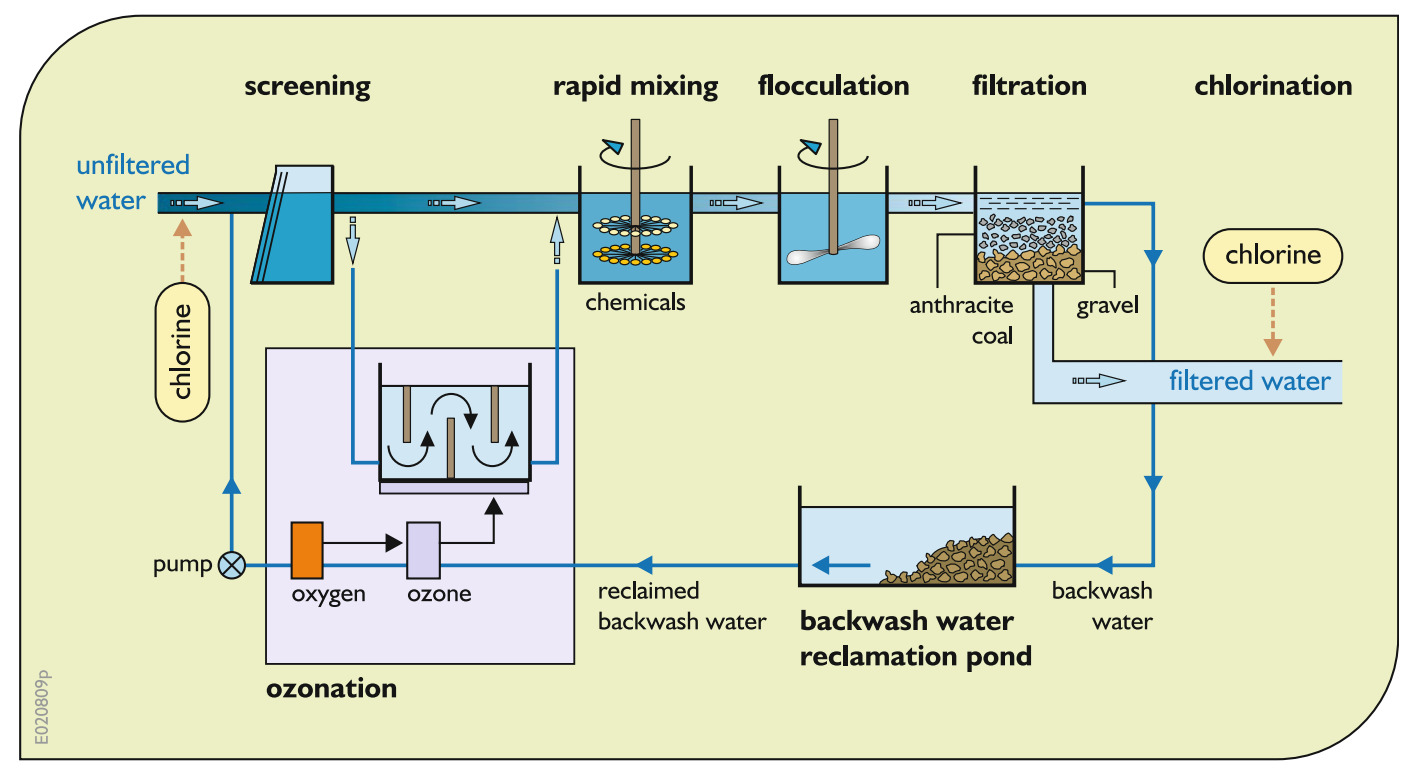

Fig. 12.2 Typical processes in water treatment plants 


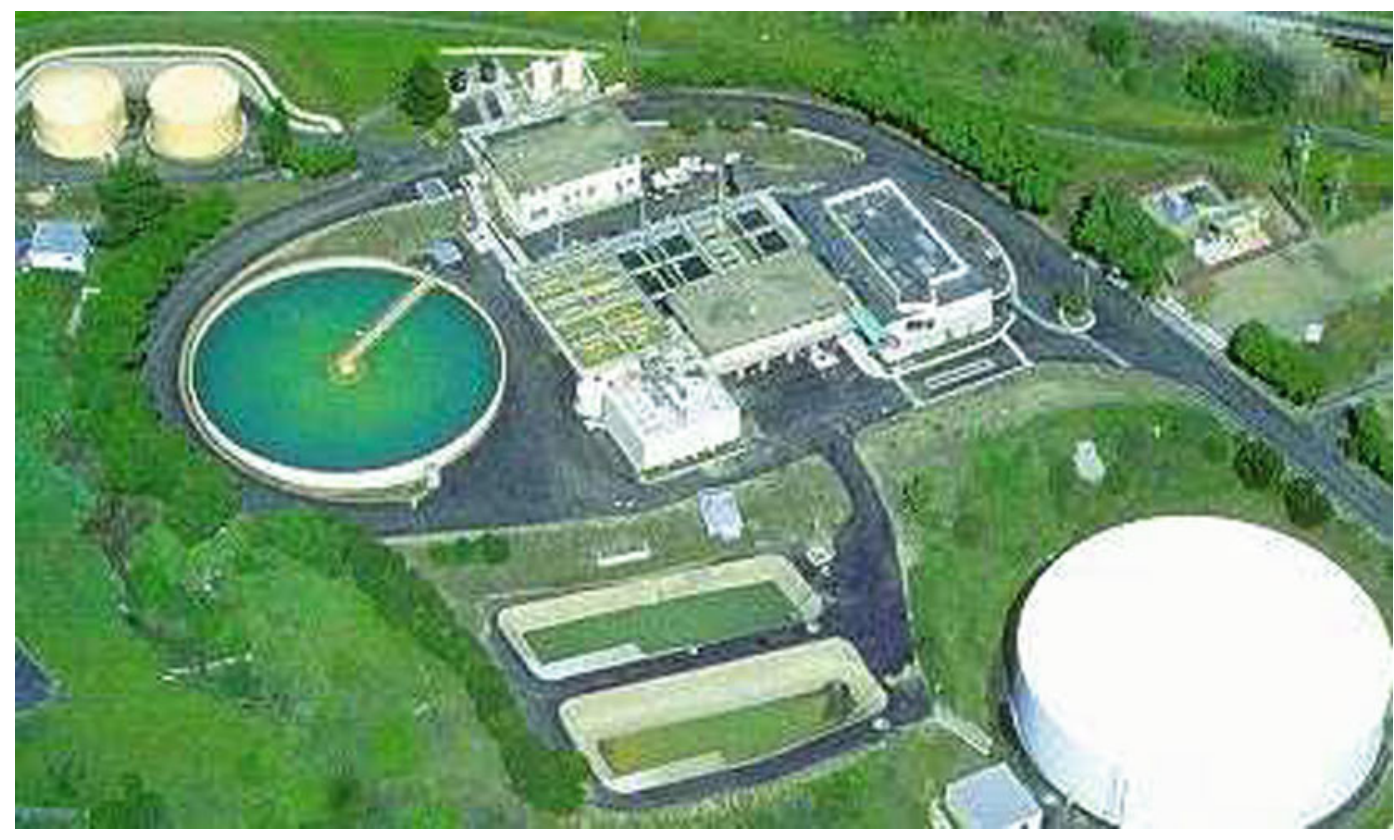

Fig. 12.3 A 6-million gallon per day water treatment plant at San Luis Obispo, located about halfway between Los Angeles and San Francisco on the Central Coast of California

Figure 12.3 is an aerial view of a water treatment plant serving a population of about 50,000 .

\subsection{Water Distribution}

Water distribution systems include pumping stations, distribution storage, and distribution piping. The hydraulic performance of each component in the distribution network depends upon the performance of other components. Of interest to designers are both the flows and their pressures throughout the network.

The energy at any point within a network of pipes is often represented in three parts: the pressure head, $p / \gamma$, the elevation head, $Z$, and the velocity head, $V^{2} / 2 g$. (A more precise representation includes a kinetic energy correction factor, but that factor is small and can be ignored.) For open-channel flows, the elevation head is the distance from some datum to the top of the water surface. For pressure pipe flow, the elevation head is the distance from some datum to the center of the pipe. The parameter $p$ is the pressure, e.g., newton per cubic meter $\left(\mathrm{N} / \mathrm{m}^{3}\right), \gamma$ is the specific weight $\left(\mathrm{N} / \mathrm{m}^{2}\right)$ of water, $Z$ is the elevation above some base elevation $(\mathrm{m}), V$ is the velocity $(\mathrm{m} / \mathrm{s})$, and $g$ is the gravitational acceleration $\left(9.81 \mathrm{~m} / \mathrm{s}^{2}\right)$.

Energy can be added to the system such as by a pump, and lost from the system such as by friction. These changes in energy are referred to as head gains and losses. Balancing the energy across any two sites $i$ and $j$ in the system requires that the total heads, including any head gains $H_{\mathrm{G}}$ and losses $H_{\mathrm{L}}(\mathrm{m})$ are equal.

$$
\begin{aligned}
& {\left[p / \gamma+Z+V^{2} / 2 g+H_{\mathrm{G}}\right]_{\text {site } i}} \\
& \quad=\left[p / \gamma+Z+V^{2} / 2 g+H_{\mathrm{L}}\right]_{\text {site } j}
\end{aligned}
$$

The hydraulic grade is the sum of the pressure head and elevation head $(p / \gamma+Z)$. For open-channel flow the hydraulic grade is the water surface slope, since the pressure head at its surface is 0 . For a pressure pipe, the hydraulic head is the height to which a water column would rise in a piezometer - a tube rising from 
the pipe. When plotted in profile along the length of the conveyance section, this is often referred to as the hydraulic grade line, or HGL. The hydraulic grade lines for open-channel and pressure pipes are illustrated in Figs. 12.4 and 12.5 .

The energy grade is the sum of the hydraulic grade and the velocity head. This is the height to which a column of water would rise in a Pitot tube, but also accounting for fluid velocity. When plotted in profile, as in Fig. 12.5, this is often referred to as the energy grade line, or EGL. At a lake or reservoir, where the velocity is essentially zero, the EGL is equal to the HGL.

Specific energy, $E$, is the sum of the depth of flow and the velocity head, $V^{2} / 2 \mathrm{~g}$. For open-channel flow, the depth of flow, $y$, is the elevation head minus the channel bottom elevation. For a given discharge, the specific energy is solely a function of channel depth. There may be

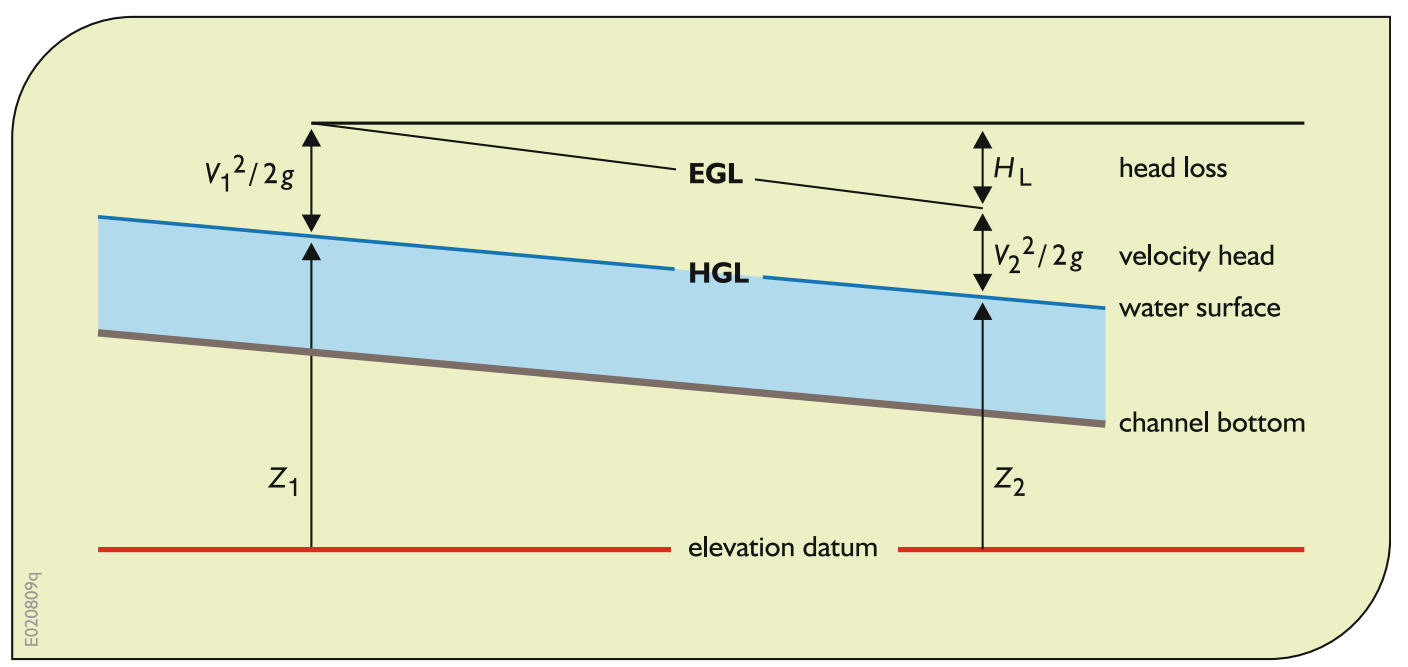

Fig. 12.4 The energy components along an open channel

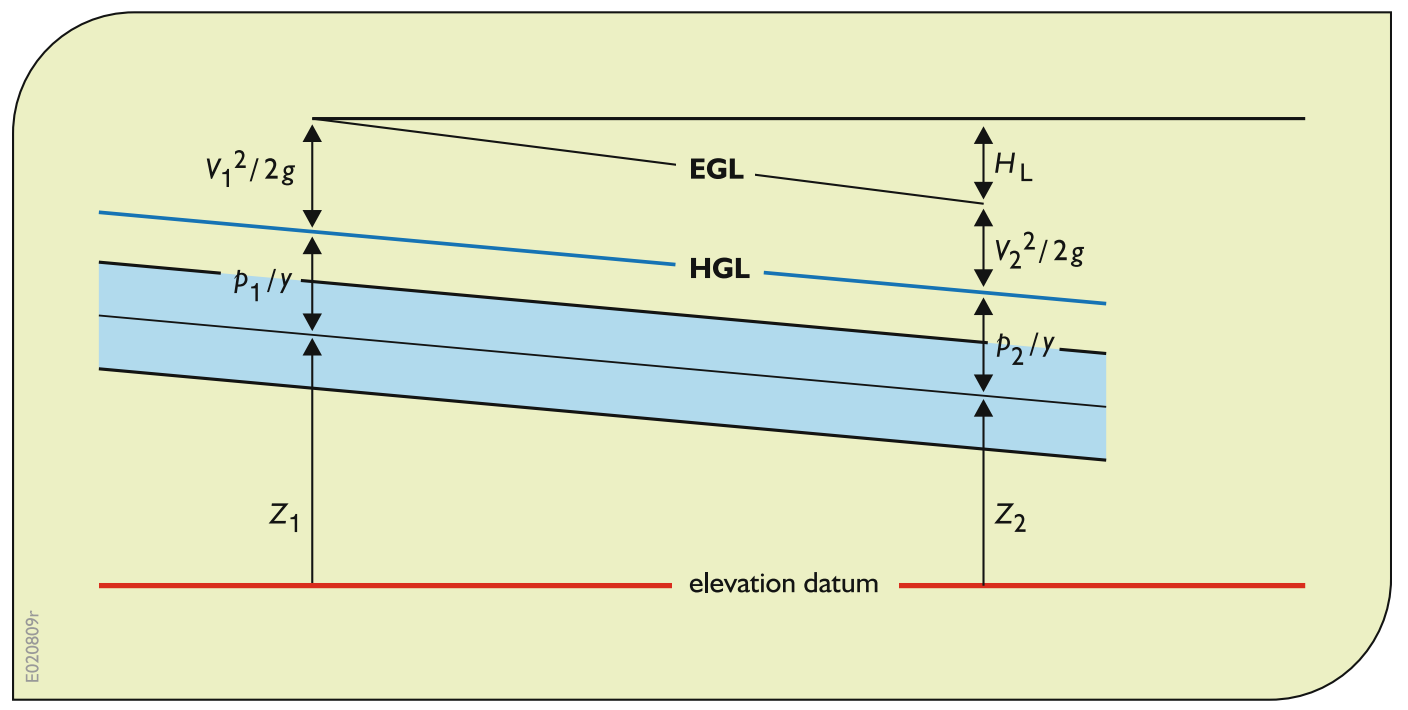

Fig. 12.5 The energy components along a pressure pipe 
more than one depth having the same specific energy. In one case the flow is subcritical (relatively higher depths, lower velocities) and in the other case the flow is critical (relatively lower depths and higher velocities). Whether or not the flow is above or below the critical depth (the depth that minimizes the specific energy) will depend in part on the channel slope.

Friction is the main cause of head loss. There are many equations that approximate friction loss associated with fluid flow through a given section of channel or pipe. These include Manning's or Strickler's equation that is commonly used for open-channel flow and Chezy's or Kutter's equation, Hazen-Williams equation, and DarcyWeisbach or Colebrook-White equations that are used for pressure pipe flow. They all define flow velocity, $V(\mathrm{~m} / \mathrm{s})$ as an empirical function of a flow resistance factor, $C$, the hydraulic radius (cross-sectional area divided by wetted perimeter), $R$, and the friction or energy slope, $S=H_{\mathrm{L}}$ / Length.

$$
V=k C R^{x} S^{y}
$$

The terms $k, x$, and $y$ of Eq. 12.2 are parameters. The roughness of the flow channel usually determines the flow resistance or roughness factor $C$. The value of $C$ may also be a function of the channel shape, depth, and fluid velocity. Values of $C$ for different types of pipes are listed in hydraulics texts or handbooks (e.g., Mays 2000, 2001; Chin 2000).

\subsubsection{Open-Channel Networks}

For open-channel flow Manning's or Strickler's equation is commonly used to predict the average velocity, $V(\mathrm{~m} / \mathrm{s})$, and the flow, $Q\left(\mathrm{~m}^{3} / \mathrm{s}\right)$ associated with a given cross-sectional area, $A\left(\mathrm{~m}^{2}\right)$. The velocity depends on the hydraulic radius $R(\mathrm{~m})$ and the slope $S$ of the channel as well as a friction factor $n$.

$$
\begin{gathered}
V=\left(R^{2 / 3} S^{1 / 2}\right) / n \\
Q=A V
\end{gathered}
$$

The values of various friction factors $n$ can be found in tables in hydraulics texts and handbooks.

The energy balance between two ends of a channel segment is defined in Eq. 12.5. For open-channel flow the pressure heads are 0 . Thus for a channel containing water flowing from site $i$ to site $j$ :

$$
\left[Z+V^{2} / 2 g\right]_{\text {site } i}=\left[Z+V^{2} / 2 g+H_{\mathrm{L}}\right]_{\text {site } j}
$$

The head loss $H_{\mathrm{L}}$ is assumed to be primarily due to friction.

The friction loss is computed based on the average rate of friction loss along the segment and the length of the segment. This is the difference in the energy grade line elevations (EGL) between sites $i$ and $j$.

$$
\begin{aligned}
H_{\mathrm{L}} & =\left(\mathrm{EGL}_{\mathrm{i}}-\mathrm{EGL}_{\mathrm{j}}\right) \\
& =\left[Z+V^{2} / 2 g\right]_{\text {site } i}-\left[Z+V^{2} / 2 g\right]_{\text {site } j}
\end{aligned}
$$

The friction loss per unit distance along the channel is the average of the friction slopes at the two ends divided by the channel length. This defines the energy grade line, EGL.

\subsubsection{Pressure Pipe Networks}

The Hazen-Williams equation is commonly used to predict the flows or velocities in pressure pipes. Flows and velocities are again dependent on the slope, $S$, the hydraulic radius $R(\mathrm{~m})$ (that equals the half the pipe radius, $r$ ), and the cross-sectional area, $A\left(\mathrm{~m}^{2}\right)$. 


$$
\begin{gathered}
V=0.849 C R^{0.63} S^{0.54} \\
Q=A V=\pi r^{2} V
\end{gathered}
$$

The head loss along a length $L(\mathrm{~m})$ of pipe of diameter $D(\mathrm{~m})$ containing a flow of $Q\left(\mathrm{~m}^{3} / \mathrm{s}\right)$ is defined as

$$
H_{\mathrm{L}}=K Q^{1.85}
$$

where $K$ is the pipe coefficient defined by Eq. 12.10.

$$
K=[10.66 L] /\left[C^{1.85} D^{4.87}\right]
$$

Another pipe flow equation for head loss is the Darcy-Weisbach equation based on a friction factor $f$.

$$
H_{\mathrm{L}}=f L V^{2} / D 2 g
$$

The friction factor is dependent on the Reynolds number and the pipe roughness and diameter.

Given these equations it is possible to compute the distribution of flows and heads throughout a network of open channels or pressure pipes. The two conditions are the continuity of flows at each node, and the continuity of head losses in loops for each time period $t$.

At each node $i$ :

$$
\text { Storage }_{\mathrm{it}}+Q_{\mathrm{it}}^{\text {in }}-Q_{\mathrm{it}}^{\text {out }}=\text { Storage }_{\mathrm{i}, \mathrm{t}+1}
$$

In each section between nodes $i$ and $j$ :

$$
H_{\mathrm{Lit}}=H_{\mathrm{Ljt}}+H_{\mathrm{Lijt}},
$$

where the head loss between nodes $i$ and $j$ is $H_{\text {Lijt }}$.

To compute the flows and head losses at each node in Fig. 12.6 requires two sets of equations, one for continuity of flows, and the other continuity of head losses. In this example, the direction of flow in two links, from $A$ to $C$, and from $B$ to $C$ are assumed unknown and hence each is represented by two nonnegative flow variables.

Let $Q_{i j}$ be the flow from site $i$ to site $j$ and $H \mathrm{i}$ be the head at site $i$. Continuity of flow in this network requires:

$$
0.5=Q_{D A}+Q_{D C}
$$

$$
\begin{gathered}
0.1=Q_{D A}-Q_{A C}+Q_{C A}-Q_{A B} \\
0.25=Q_{A B}+Q_{C B}-Q_{B C} \\
0.15=Q_{D C}+Q_{A C}-Q_{C A}+Q_{B C}-Q_{C B}
\end{gathered}
$$

Continuity of heads at each node requires:
Fig. 12.6 An example of a pipe network, showing the values of $K$ for predicting head losses from Eq. 12.10

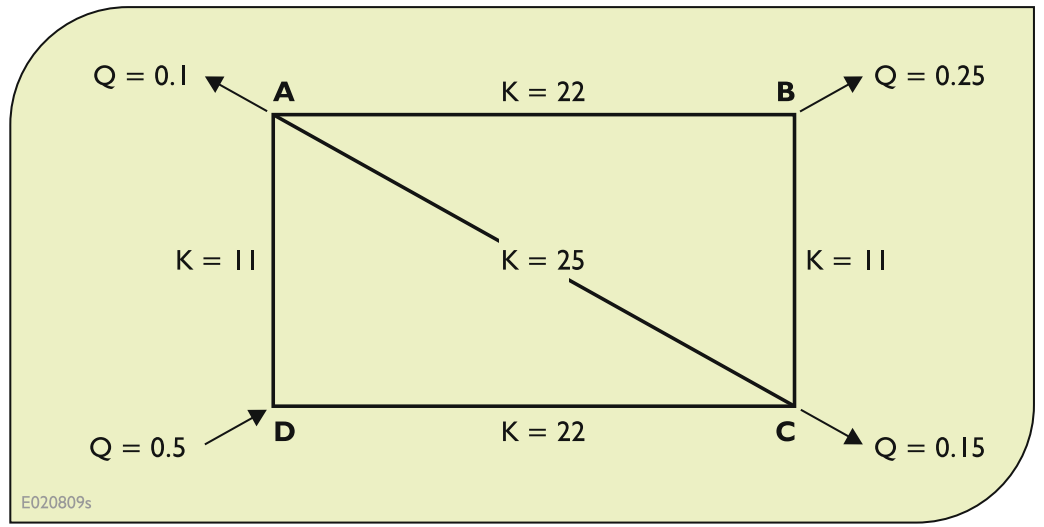




$$
\begin{gathered}
H_{\mathrm{D}}=H_{\mathrm{C}}+22 *\left(Q_{D C}^{1.85}\right) ; \\
H_{\mathrm{D}}=H_{\mathrm{A}}+11 *\left(Q_{D A}^{1.85}\right) ; \\
H_{\mathrm{A}}=H_{\mathrm{B}}+22 * Q_{A B}^{1.85} ; \\
H_{\mathrm{C}}=H_{\mathrm{A}}+25 *\left(\left(Q_{C A}-Q_{A C}\right)^{1.85}\right) ; \\
H_{\mathrm{C}}=H_{\mathrm{B}}+11 *\left(\left(Q_{C B}-Q_{B C}\right)^{1.85}\right)
\end{gathered}
$$

Solving these Eqs. 12.14-12.22 simultaneously for the five flow and four head variables yields the flows $Q_{i j}$ from nodes $i$ to nodes $j$ and heads $H_{\mathrm{i}}$ at nodes $i$ listed in Table 12.1.

This solution shown in Table 12.1 assumes that the network is at a constant elevation, has no storage capacity, and there are no minor losses. Losses are usually expressed as a linear function of the velocity head, due to hydraulic structures (such as valves, restrictions, or meters) at each node. This solution suggests that the pipe section between nodes $A$ and $C$ may not be economical, at least for these flow conditions. Other flow conditions may prove otherwise. But even if they do not, this pipe section increases the reliability of the system, and reliability is an important consideration in water supply distribution networks.

\subsubsection{Water Quality}

Many of the water quality models discussed in Chap. 10 can be used to predict water quality constituent concentrations in open channels and in pressure pipes. The assumption of complete mixing such as at junctions or in short segments of pipe, is made. Reactions among constituents can occur as water travels through the system at predicted velocities. Water-resident times (the ages of waters) in various parts of the network are important variables for water quality prediction as constituent decay, transformation, and growth processes take place over time.

Computer models typically use numerical methods to find the hydraulic flow and head relationships as well as the resulting water quality concentrations. Most numerical models

Table 12.1 Flows and heads of the network shown in Fig. 12.6

$$
\begin{aligned}
& Q_{D A}=0.29 \\
& Q_{D C}=0.21 \\
& Q_{A C}=0.07 \\
& Q_{C A}=0.00 \\
& Q_{A B}=0.12 \\
& Q_{C B}=0.13 \\
& Q_{B C}=0.00 \\
& H_{A}=0.43 \\
& H_{B}=0.00 \\
& H_{C}=0.26 \\
& H_{D}=1.52
\end{aligned}
$$


assume combinations of plug flow (advection) along pipe sections and complete mixing within segments of the each pipe section at the end of each simulation time step. Some models also use Lagrangian approaches for tracking particles of constituents within a network. (See Chap. 10).

Computer programs (e.g., EPANET) exist that can perform simulations of the flows, heads, and water quality behavior within pressurized networks of pipes, pipe junctions, pumps, valves, and storage tanks or reservoirs. These programs are designed to predict the movement and fate of water constituents within distribution systems. They can be used for many different kinds of applications in distribution systems design, hydraulic model calibration, chlorine residual analysis, and consumer exposure assessment. They can also be used to compare and evaluate the performance of alternative management strategies for improving water quality throughout a system. These can include:

- altering the sources within multiple source systems,

- altering pumping and tank filling/emptying schedules,

- use of satellite treatment, such as rechlorination at storage tanks,

- targeted pipe cleaning and replacement.

Computer models that simulate the hydraulic and water quality processes in water distribution networks must be run long enough for the system to reach equilibrium conditions, i.e., conditions not influenced by initial boundary assumptions. Equilibrium conditions within pipes are reached relatively quickly compared to those in storage tanks.

\subsection{Wastewater Collection}

\subsubsection{Sewer Networks}

Flows in urban sewers and their pollutant concentrations vary throughout a typical day, a typical week, and over the seasons of a year. Flow conditions can range from free surface to surcharged flow, from steady to unsteady flow, and from uniform to gradually or rapidly varying non-uniform flow.

Urban drainage ditches normally have uniform cross sections along their lengths and uniform gradients. Because the dimensions of the cross sections are typically one or two orders of magnitude less than the lengths of the conduit, unsteady free surface flow can be modeled using one-dimensional flow equations.

When modeling the hydraulics of flow it is important to distinguish between the speed of propagation of the kinematic wave disturbance and the speed of the bulk of the water. In general the wave travels faster than the water particles. Thus if water is injected with a tracer the tracer lags behind the wave. The speed of the wave disturbance depends on the depth, width, and velocity of the flow.

Flood attenuation (or subsidence) is the decrease in the peak of the wave as it propagates downstream. Gravity tends to flatten, or spread out, the wave along the channel. The magnitude of the attenuation of a flood wave depends on the peak discharge, the curvature of the wave profile at the peak, and the width of flow. Flows can be distorted (changed in shape) by the particular channel characteristics.

Additional features of concern to hydraulic modelers are the entrance and exit losses to the conduit. Typically at each end of the conduit is a manhole. Manholes are storage chambers that provide access (for men and women) to the conduits upstream and downstream. Manholes induce some additional head loss.

Manholes usually cause a major part of the head losses in sewer systems. A manhole head loss represents a combination of the and contraction losses. For pressure flow, the head loss $H_{\mathrm{L}}$ due to contraction can be written as a function of the downstream velocity, $V_{\mathrm{D}}$, and the upstream and downstream flow cross-sectional areas $A_{\mathrm{U}}$ and $A_{\mathrm{D}}$.

$$
H_{\mathrm{L}}=K\left(V_{\mathrm{D}}^{2} / 2 g\right)\left[1-\left(A_{\mathrm{D}} / A_{\mathrm{U}}\right)\right]^{2}
$$

The coefficient $K$ varies between 0.5 for sudden contraction and about 0.1 for a well-designed gradual contraction. 
An important parameter of a given open-channel conduit is its capacity, that is, the maximum flow that can occur without surcharging or flooding. Assuming the hydraulic gradient is parallel to the bed of the conduit, each conduit has an upper limit to the flow that it can accept.

Pressurized flow is much more complex than free surface flow. In marked contrast to the propagation speed of disturbances under free surface flow conditions, the propagation of disturbances under pressurized flow in a $1 \mathrm{~m}$ circular conduit $100 \mathrm{~m}$ long can be less than a second. Some conduits can have the stable situation of free surface flow upstream and pressurized flow downstream.

\subsection{Wastewater Treatment}

The wastewater generated by residences, businesses, and industries in a community is largely water. Wastewater often contains less than $10 \%$ dissolved and suspended solid material. Its cloudiness is caused by suspended particles whose concentrations in untreated sewage range from 100 to $350 \mathrm{mg} / \mathrm{l}$. One measure of the biodegradable constituents in the wastewater is its biochemical oxygen demand, or $B O D_{5} . B O D_{5}$ is the amount of dissolved oxygen aquatic microorganisms consumed in 5 days as they metabolize (eat) the organic material in the wastewater. Untreated sewage typically has a $B O D_{5}$ concentration ranging from 100 to $300 \mathrm{mg} / \mathrm{l}$.

Pathogens or disease-causing organisms are also present in sewage. Coliform bacteria are used as an indicator of disease-causing organisms. Sewage also contains nutrients (such as ammonia and phosphorus), minerals, and metals. Ammonia can range from 12 to $50 \mathrm{mg} / \mathrm{l}$ and phosphorus can range from 6 to $20 \mathrm{mg} / \mathrm{l}$ in untreated sewage (Fig. 12.8).

As illustrated in Fig. 12.7, wastewater treatment is a multistage process. The goal is to reduce or remove organic matter, solids, nutrients, disease-causing organisms, and other pollutants from wastewater before it is released into a body of water, or on to the land, or is reused.
The first stage of treatment is called preliminary treatment.

Preliminary treatment removes solid materials (sticks, rags, large particles, sand, gravel, toys, money, or anything people flush down toilets). Equipment such as bar screens, and grit chambers are used to filter the wastewater as it enters a treatment plant. The wastewater then passes on to what is called primary treatment.

Clarifiers and septic tanks are usually used to provide primary treatment. Primary treatment separates suspended solids and greases from wastewater. Wastewater is held in a tank for several hours allowing the particles to settle to the bottom and the greases to float to the top. The solids drawn off the bottom and skimmed off the top receive further treatment as sludge. The clarified wastewater flows on to the next secondary stage of wastewater treatment.

Secondary treatment is typically a biological treatment process designed to remove dissolved organic matter from wastewater. Sewage microorganisms cultivated and added to the wastewater absorb organic matter from sewage as their food supply. Three approaches are commonly used to accomplish secondary treatment; fixed film, suspended film, and lagoon systems.

Fixed film systems grow microorganisms on substrates such as rocks, sand, or plastic. The wastewater is spread over the substrate. As organic matter and nutrients are absorbed from the wastewater, the film of microorganisms grows and thickens. Trickling filters, rotating biological contactors, and sand filters are examples of fixed film systems.

Suspended film systems stir and suspend microorganisms in wastewater. Activated sludge, extended aeration, oxidation ditch, and sequential batch reactor systems are all examples of suspended film systems. As the microorganisms absorb organic matter and nutrients from the wastewater they grow in size and number. After the microorganisms have been suspended in the wastewater for several hours, they are settled out as sludge. Some of the sludge is pumped back into the incoming wastewater to provide "seed" microorganisms. The remainder is sent on to a sludge treatment process. 


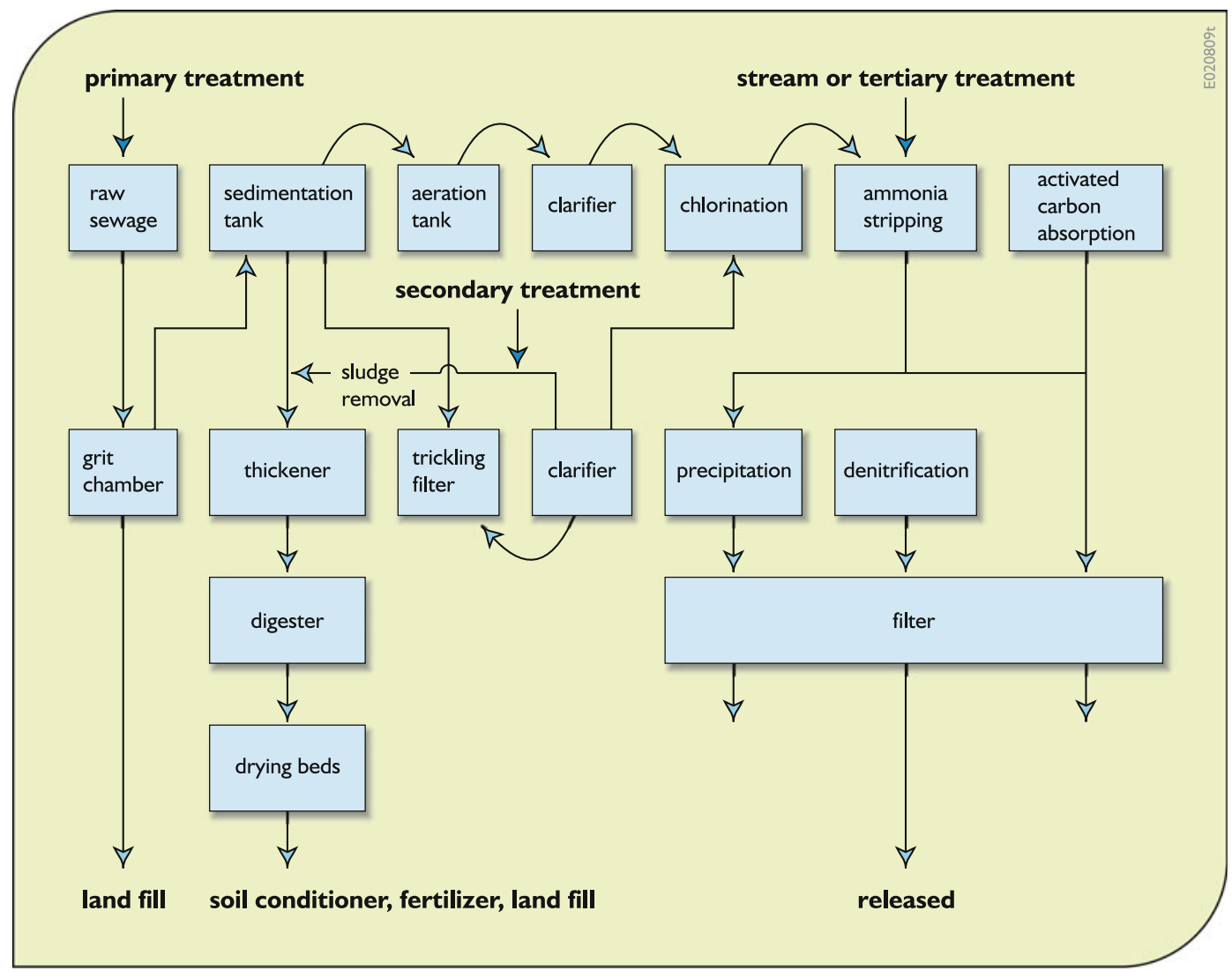

Fig. 12.7 A typical wastewater treatment plant showing the sequence of processes for removing impurities

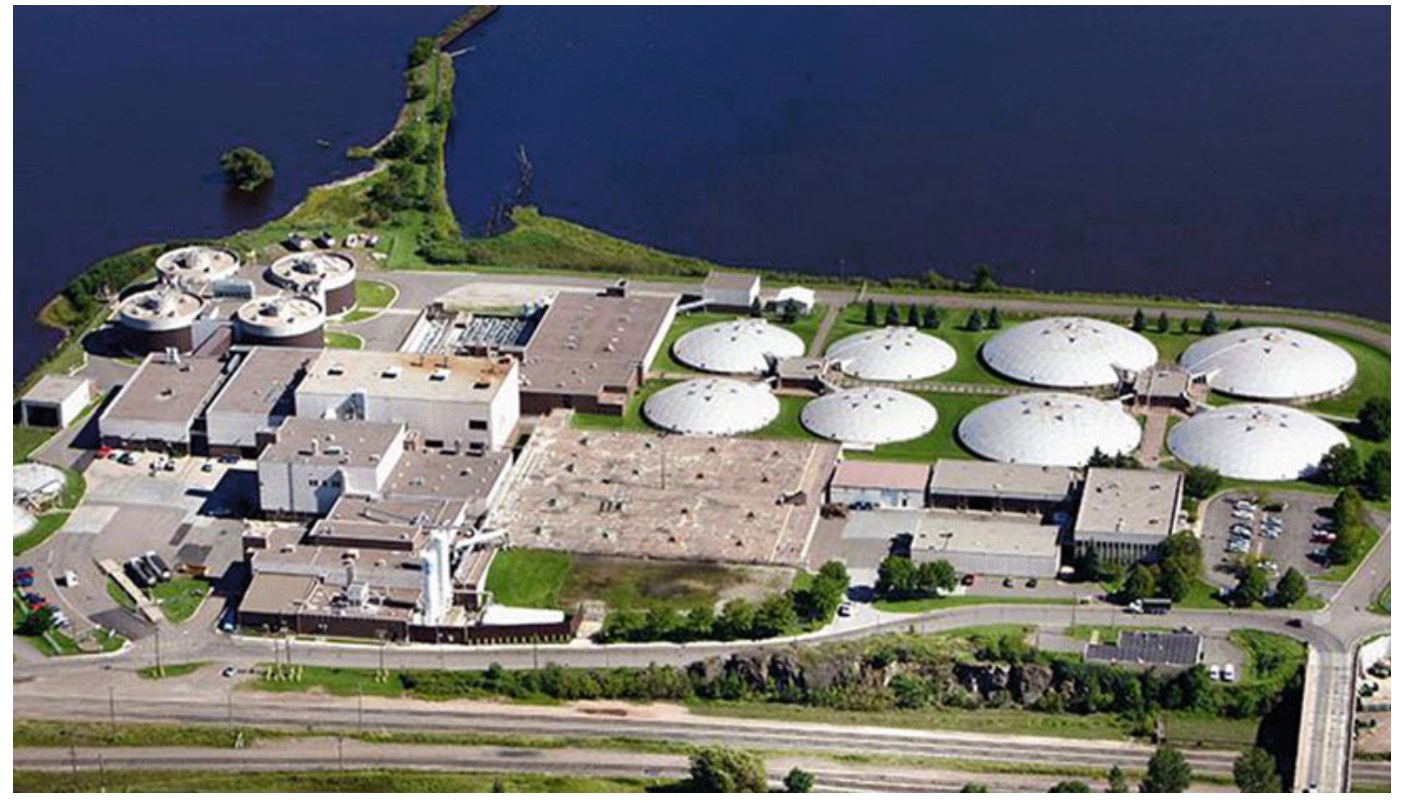

Fig. 12.8 Wastewater treatment plant on the shores of Western Lake Superior in Minnesota, USA. The Activated Sludge system is designed to treat 48 million gallons of wastewater per day (mgd) with a peak hydraulic capacity of $160 \mathrm{mgd}$. (Photo courtesy of Western Lake Superior Sanitary District.) 
Lagoons, where used, are shallow basins that hold the wastewater for several months to allow for the natural degradation of sewage. These systems take advantage of natural aeration and microorganisms in the wastewater to renovate sewage.

Advanced treatment is necessary in some treatment systems to remove nutrients from wastewater. Chemicals are sometimes added during the treatment process to help remove phosphorus or nitrogen. Some examples of nutrient removal systems include coagulant addition for phosphorus removal and air stripping for ammonia removal.

Final treatment focuses on removal of disease-causing organisms from wastewater. Treated wastewater can be disinfected by adding chlorine or by exposing it to sufficient ultraviolet light. High levels of chlorine may be harmful to aquatic life in receiving streams. Treatment systems often add a chlorine-neutralizing chemical to the treated wastewater before stream discharge.

Sludges are generated throughout the sewage treatment process. This sludge needs to be treated to reduce odors, remove some of the water and reduce volume, decompose some of the organic matter and reduce volume, and kill diseasecausing organisms. Following sludge treatment, liquid and cake sludge free of toxic compounds can be spread on fields, returning organic matter and nutrients to the soil.

\subsection{Urban Drainage Systems}

Urban drainage involves a number of hydraulic and biochemical processes. These typically include:

- Rainfall and surface runoff

- Surface loading and washoff of pollutants

- Stormwater sewer and pipe flow

- Sediment transport

- Separation of solids at structures

- Outfalls

These components or processes are briefly discussed in the following subsections.

\subsubsection{Rainfall}

Surface runoff of precipitation and the need to collect urban wastewater are the primary reasons for designing and maintaining urban drainage systems. Storms are a major source of flow into the system. Even sanitary sewer systems that are designed to be completely separate from storm drainage sewers are often influenced by rainfall through illicit connections or even infiltration.

Rainfall varies over time and space. These differences are normally small when considering short time periods and small distances but they increase as time and distance increase. The ability to account for spatial differences in rainfall depends on the size of the catchment area and on the number of functioning rainfall recording points in the catchment. The use of radar permits more precision in estimating precipitation patterns over space and time, as if more rain gauges were used and as if they were monitored more frequently. In practice spatial effects are not measured at high resolution and therefore events where significant spatial variations occur, such as in summer thunderstorms, are usually not very accurately represented.

There are two categories of rainfall records: recorded (real) events and synthetic (not-real) events. Synthetic rainfall comes in two forms: as stochastically generated rainfall data and as design storms. These events are derived from analyses of actual rainfall data and are used to augment or replace those historical (real) data.

Design events are a synthesized set of rainfall profiles that have been processed to produce storms with specific return periods, i.e., how often, on average, one can expect to observe rainfall events of that magnitude or greater. Design events are derived to reduce the number of runs needed to analyze system performance under design flow conditions.

\subsubsection{Time Series Versus Design Storms}

Professionals can argue over whether infrastructure design capacities should be based on real rainfall records or synthetic storm events. The 
argument in favor of using synthetic storms is that they are easy to use and require only a few events to assess the system design performance. The argument in favor of a time series of real rainfall is that these data typically include a wider range of conditions, and therefore are likely to contain the conditions that are critical on each catchment.

The two methods are not contradictory. The use of real rainfall involves some synthesis in choosing which storms to use in a time series, and in adjusting them for use on a catchment other than the one where they were measured. Time series of rainfalls are generally used to look at aspects such as overflow spill frequencies and volumes. On the other hand, synthetic design storms can be generated for a wide range of conditions including the same conditions as represented by real rainfall. This is generally considered appropriate for looking at pipe network performance.

\subsubsection{Spatial-Temporal Distributions}

Rainfall varies in space as well as in time, and the two effects are related. Short duration storms typically come from small rain cells that have a short life, or that move rapidly over the catchment. As these cells are small (of the order of a kilometer in diameter) there is significant spatial variation in rainfall intensity. Longer duration storms tend to come from large rainfall cells associated with large weather systems. These have less spatial intensity variation.

Rainfall is generally measured at specific sites using rain gauges. The recorded rainfall amount and intensity will not be the same at each site. Thus the use of recorded rainfall data requires some way to account for this spatial and temporal variations. The average rainfall over the catchment in any period of time can be more or less than the measured values at one or more gauge sites. The runoff from a portion of a catchment exposed to a high intensity rainfall will more than the runoff from the same amount of rainfall spread evenly over the entire catchment.

\subsubsection{Synthetic Rainfall}

A convenient way of using rainfall data is to analyze long rainfall records to define the statistical characteristics of the rainfall, and then to use these statistics to produce synthetic rainstorms of various return periods and durations.

Three parameters are used to describe the statistics of rainfall depth.

- The rainfall intensity or depth of rain in a certain period

- The length of the period over which that intensity occurs

- The frequency with which it is likely to occur, or the probability of it occurring in any particular year.

In most of the work on urban drainage and river modeling, the risks of occurrence are expressed not by probabilities but by the inverse of probability, the return period. An event that has a probability of 0.2 of being equaled or exceeded each year has an expected return period of $1 / 0.2$ or 5 years. An event having a probability of 0.5 of being equaled or exceeded has an expected return period of $1 / 0.5=2$ years.

Rainfall data show an intensity-duration-frequency relationship. The intensity and duration are inversely related. As the rainfall duration increases the intensity reduces. The frequency and intensity are inversely related so that as the event becomes less frequent the intensity increases.

An important part of this duration-intensity relationship is the period of time over which the intensity is averaged. It is not necessarily the length of time for which it rained from start to finish. In fact any period of rainfall can be analyzed for a large range of durations, and each duration could be assigned a different return period. The largest return period might be quoted as the "return period of the storm", but it is only meaningful when quoted with its duration.

Intensity-duration-frequency relationships or depth-duration-frequency relationships, as shown in Fig. 12.9, are derived by analysis of a long set of rainfall records. Intensity-durationfrequency data is commonly available all over the world and therefore it is important to be aware of its method of derivation and ways it can be used for simulation modeling. 
Fig. 12.9 Rainfall intensity-durationfrequency (return period) curves

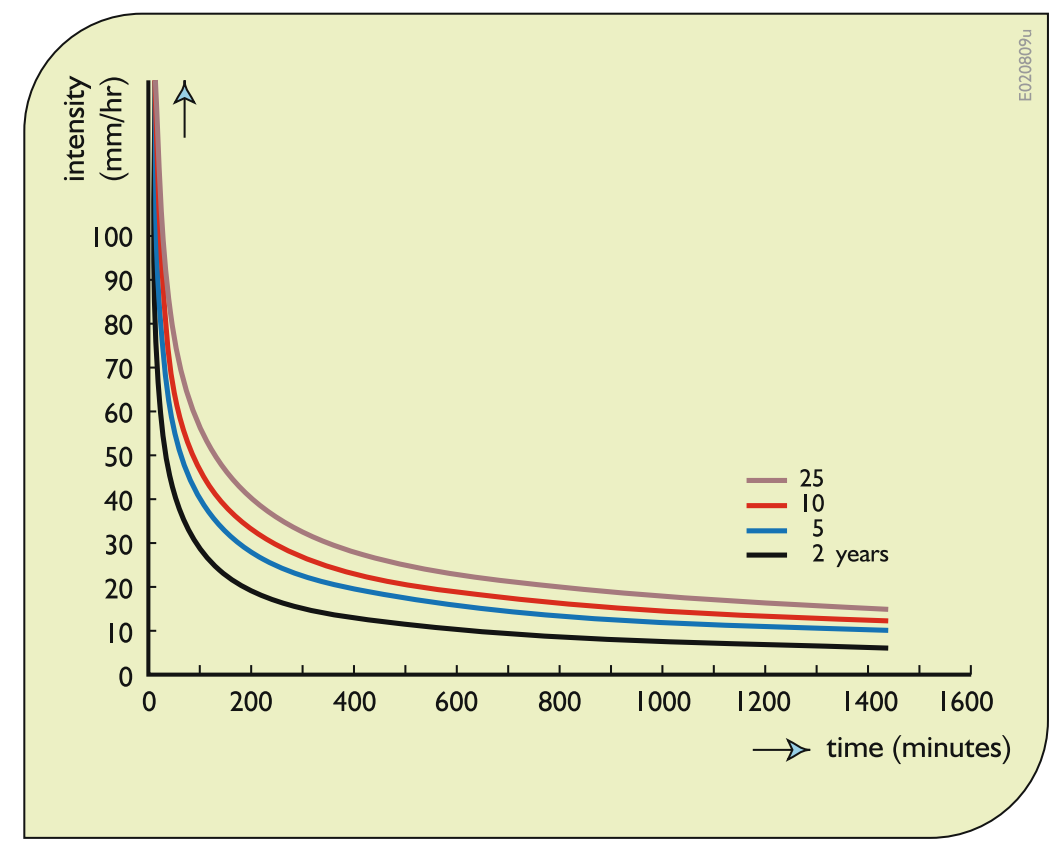

The depth of rainfall is the intensity times its duration integrated over the total storm duration.

\subsubsection{Design Rainfall}

Design rainfall events (hyetographs) for use in simulation models are derived from intensityduration-frequency data.

The rainfall intensity during an event is not uniform in time, and its variation both in intensity and when the peak intensity occurs during the storm can be characterized by the peakedness of the storm and the skew of the storm (Fig. 12.10).

A design storm is a synthetic storm that has an appropriate peak intensity and storm profile.

\subsubsection{Runoff}

The runoff from rainfall involves a number of processes and events, as illustrated in Fig. 12.11, and can be modeled using various methods. Most of these methods assume an initial loss, a continuing loss, and a remainder contributing to the system runoff.
Most models assume that the first part of a rainfall event goes to initial wetting of surfaces and filling depression storage. The depth assumed to be lost is usually related to the surface type and condition. Rain water can be intercepted by vegetation or can be trapped in depressions on the ground surface. It then either infiltrates into the ground and/or evaporates. Depression storage can occur on any surface, paved, or otherwise.

Initial loss depths are defined as the minimum quantity of rainfall causing overland runoff. The initial loss depth of rainfall for catchment surfaces can be estimated as the intercept on the rainfall axis of plots of rainfall verses runoff (Fig. 12.12). The runoff values shown in Fig. 12.12 were obtained for various catchments in the UK (Price 2002).

As rainfall increases so does depression storage. The relationship between depression storage and surface slope $S$ is assumed to be of the form $a S^{-b}$, where $S$ is average slope of the subcatchment and $a$ and $b$ are parameters between 0 and 1 . The values of $a$ and $b$ depend in part on the surface type.

Evaporation, another source of initial loss, is generally considered to be relatively unimportant. 


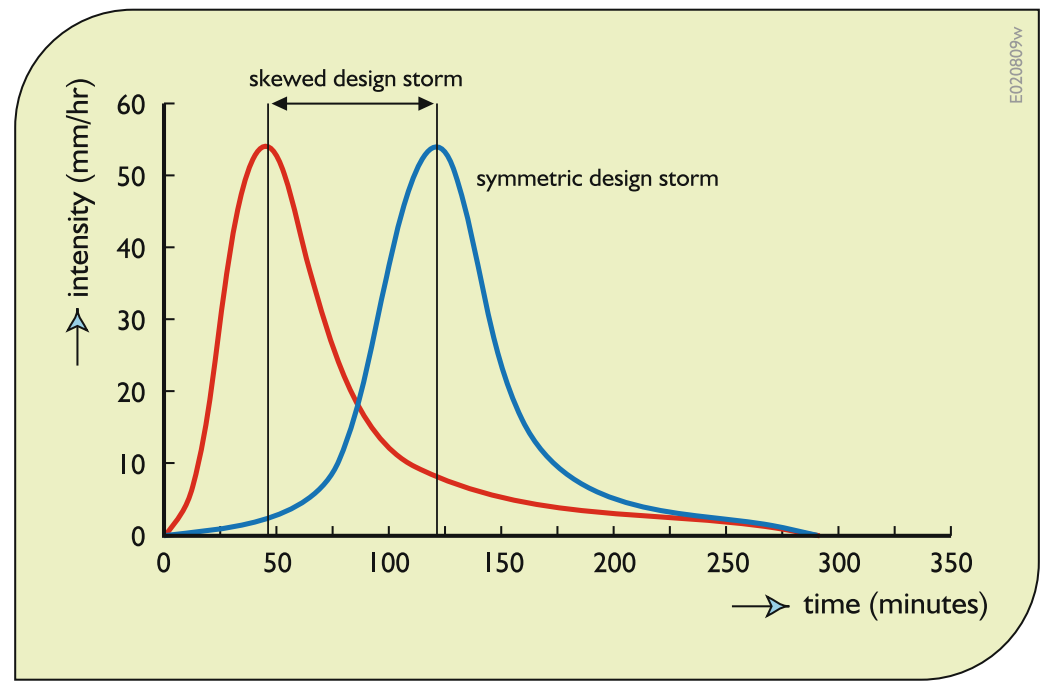

Fig. 12.10 Storm peak skewness profiles

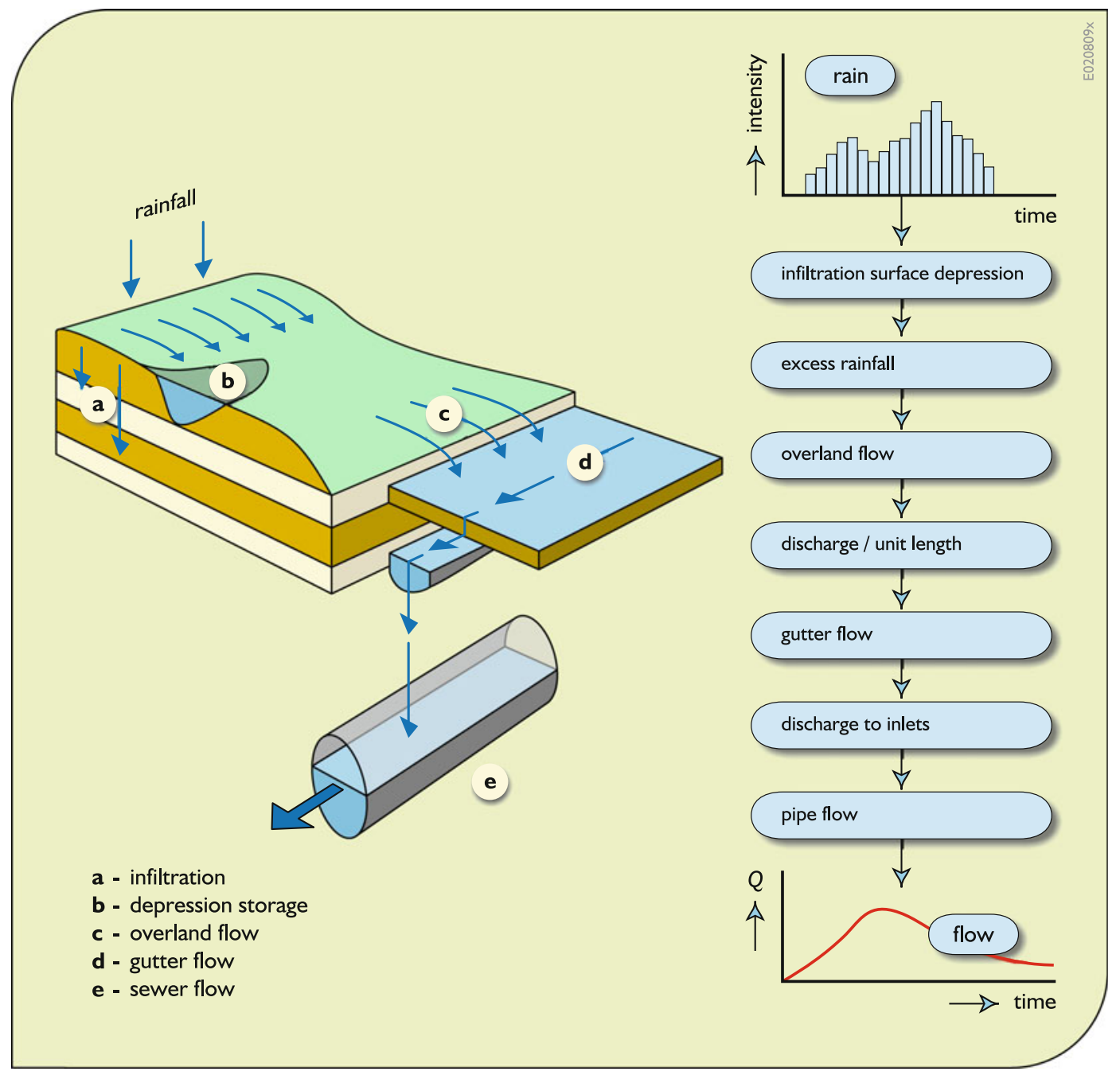

Fig. 12.11 Schematic representation of urban rainfall-runoff processes 
Fig. 12.12 Estimation of depression storage based on data from catchments in the UK (Price 2002)

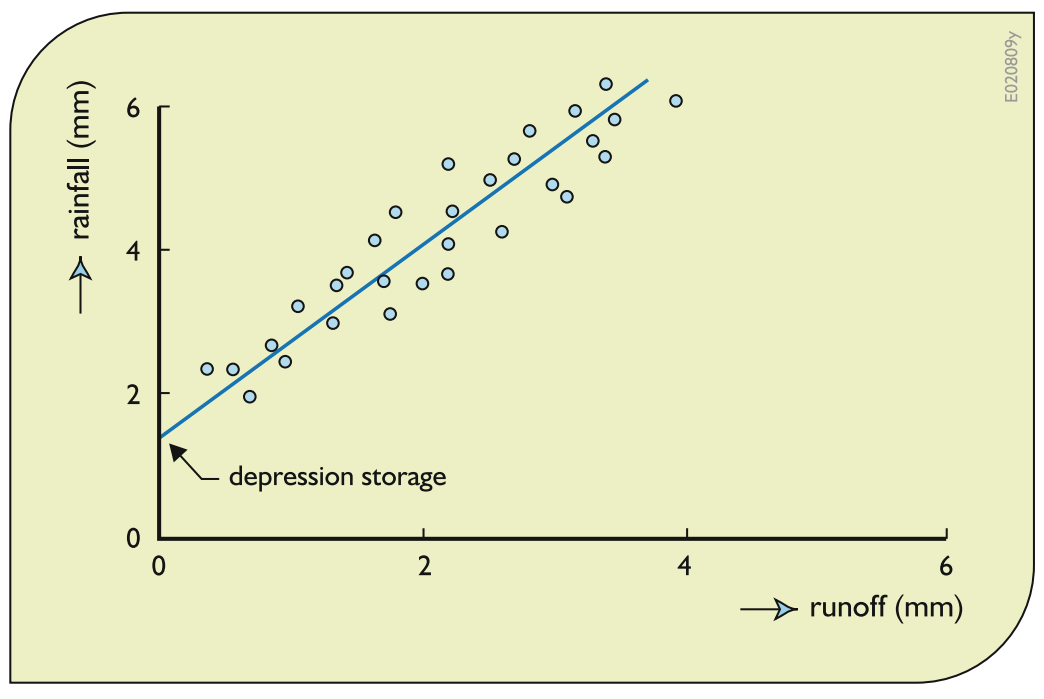

For example, considering a heavy summer storm (25 mm rainfall depth) falling on hot-asphalt (temperature say $60{ }^{\circ} \mathrm{C}$ falling to $20-30{ }^{\circ} \mathrm{C}$ as a result of sensible heat-loss) a maximum evaporation loss of $1 \mathrm{~mm}$ is likely to occur.

Continuing losses are often separated into two parts: evapotranspiration and infiltration. These processes are usually assumed to continue throughout and beyond the storm event as long as water is available on the surface of the ground. Losses due to vegetation transpiration and general evaporation are not particularly an issue for single events, but can be during the interevent periods where catchment drying takes place. This is applicable to models where time-series data are used and generated. Infiltration is usually assumed to account for the remaining rainfall that does not enter into the drainage system. The proportion of this loss can range from $100 \%$ for very permeable surfaces to $0 \%$ for completely impermeable surfaces.

Many models try to account for the wetting of the catchment and the increasing runoff that takes place as wetting increases. The effect of this is shown in Fig. 12.13.

It is impractical to take full account of the variability in urban topography, and surface condition. Impervious (paved) surfaces are often dominant in an urban catchment and the loss of rainfall prior to runoff is usually relatively small.
Runoff routing is the process of passing rainfall across the surface to enter the drainage network. This process results in attenuation and delay. These are modeled using routing techniques that generally consider catchment area size, ground slope, and rainfall intensity in determining the flow rate into the network. The topography and surface channels and even upstream parts of the sewer system are usually lumped together into this process and are not explicitly described in a model. The runoff routing process is often linked to catchment surface type and empirical calibration factors are used accordingly.

Various models for rainfall-runoff and routing are available and are used in different parts of the world. Overland runoff on catchment surfaces can be represented by the kinematic wave equation. However, direct solution of this equation in combination with the continuity equation has not been a practical approach when applied to basins with a large number of contributing subcatchments. Simpler reservoir-based models, that are less computationally and data demanding, represent the physical processes almost as accurately as the more complex physically based approaches (Price 2002). In practice, models applied to catchments typically assume an average or combined behavior of a number of overland flow planes, gutters, and feeder pipes. Therefore, the 
Fig. 12.13 Effect of catchment wetness on runoff Q over time t (Price 2002)

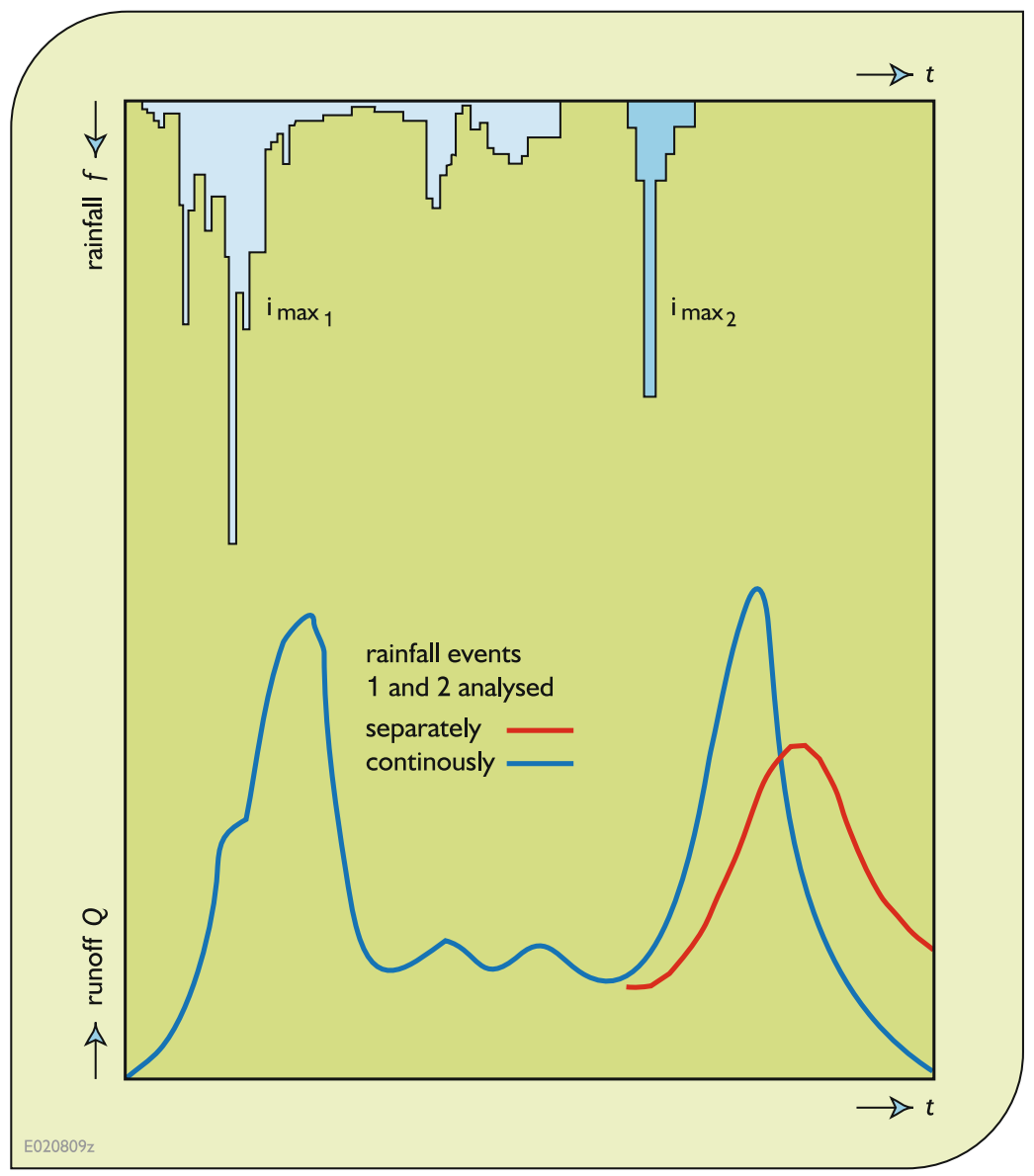

parameters of a physically based approach (for example, the roughness value) as applied would not relate directly to parameters representative of individual surfaces and structures.

Many overland flow routing models are based on a linear reservoir-routing concept. A single reservoir model assumes that the outflow, $Q$ (t) $\left(\mathrm{m}^{3} / \mathrm{s}\right)$, at the catchment outlet is proportional to the volume of stormwater, $S(t)\left(\mathrm{m}^{3}\right)$, present on the ground surface of that catchment including the nonexplicitly modeled network that contributes stormwater to that outlet point of the urban drainage system. To take into account the effects of depression storage and other initial losses, the first millimeter(s) of rainfall may not contribute to the runoff.

The basic equation for runoff $Q(t)\left(\mathrm{m}^{3} / \mathrm{s}\right)$ at time $t$ is

$$
Q(t)=S(t) / K
$$

where $K$ is a linear reservoir coefficient. This coefficientis sometimes a function of the catchment slope, area, length of longest sewer, and rainfall intensity. For a two linear reservoir model, two reservoirs are applied in series for each surface type with an equivalent storage-output relationship, as defined by Eq. 12.24, foreachreservoir.

The simplest models rely on fixed runoff coefficients $K$. They best apply to impervious areas where antecedent soil moisture conditions are not a factor.

Typical values for runoff coefficients are given in Table 12.2 (Price 2002). Use of these coefficients should be supported either by field observations or by expert judgment. 
Table 12.2 Typical values of the runoff fraction (coefficient $K$ )

\begin{tabular}{|l|l|l|}
\hline $\begin{array}{l}\text { surface } \\
\text { type }\end{array}$ & description & $\begin{array}{l}\text { coefficient } \\
K\end{array}$ \\
\hline paved & high quality paved roads with gullies $<100 \mathrm{~m}$ apart & 1.00 \\
\hline paved & high quality paved roads with gullies $>100 \mathrm{~m}$ apart & 0.90 \\
\hline paved & medium quality paved roads & 0.85 \\
\hline paved & poor quality paved roads & 0.80 \\
\hline permeable & high to medium density housing & $0.55-0.45$ \\
\hline permeable & low density housing or industrial areas & 0.35 \\
\hline permeable & open areas & $0.00-0.25$ \\
\hline
\end{tabular}

\subsubsection{The Horton Infiltration Model}

The Horton model describes the increasing runoff from permeable surfaces as a rainfall event occurs by keeping track of decreasing infiltration as the soil moisture content increases. The runoff from paved surfaces is assumed to be constant while the runoff from permeable surfaces is a function of the conceptual wetting and infiltration processes.

Based on infiltrometer studies on small catchments Horton defined the infiltration rate, $f$, either on pervious surfaces or on semipervious surfaces, as a function of time, $t$ (hours), the initial infiltration rate, $f_{\mathrm{o}}(\mathrm{mm} / \mathrm{h})$, the minimum (limiting or critical) infiltration rate, $f_{\mathrm{c}}(\mathrm{mm} / \mathrm{h})$, and an infiltration rate constant, $k(1 / \mathrm{h})$.

$$
f=f_{\mathrm{c}}+\left(f_{\mathrm{o}}-f_{\mathrm{c}}\right) e^{-k t}
$$

The minimum or limiting infiltration rate, $f_{\mathrm{c}}$, is commonly set to the saturated groundwater hydraulic conductivity for the applicable soil type.
The integration of Eq. 12.25 over time defines the cumulative infiltration $F(t)$.

$$
F(t)=f_{\mathrm{c}} t+\left(f_{\mathrm{o}}-f_{\mathrm{c}}\right)\left(1-\mathrm{e}^{-k t}\right) / k
$$

The Horton equation variant as defined in Eq. 12.26 represents the potential infiltration depth, $F$, as a function of time, $t$, assuming the rainfall rate is not limiting, i.e., it is higher than the potential infiltration rate. Expressed as a function of time, it is not suited for use in a continuous simulation model. The infiltration capacity should be reduced in proportion to the cumulative infiltration volume, $F$, rather than in proportion to time. To do this Eq. 12.26 may be solved iteratively to find the time it takes to cause ponding, $t_{p}$, as a function of $F$. That time $t_{p}$ is used in Eq. 12.25 to establish the appropriate infiltration rate for the next time interval (Bedient and Huber 1992). This procedure is used, for example, in the urban stormwater management model (SWMM) (Huber and Dickinson 1988). 
A flow chart of the calculations performed in a simulation program in which the rainfall can vary might be as shown in Fig. 12.14.

Various values for Horton's infiltration model are available in the published literature. Values of $f_{\mathrm{o}}$ and $f_{\mathrm{c}}$ as determined by infiltrometer studies,
Table 12.3 , are highly variable even by an order of magnitude on seemingly similar soil types. Furthermore, the direct transfer of values as measured on rural catchments to urban catchments is not advised due to the compaction and vegetation differences associated with the latter surfaces.

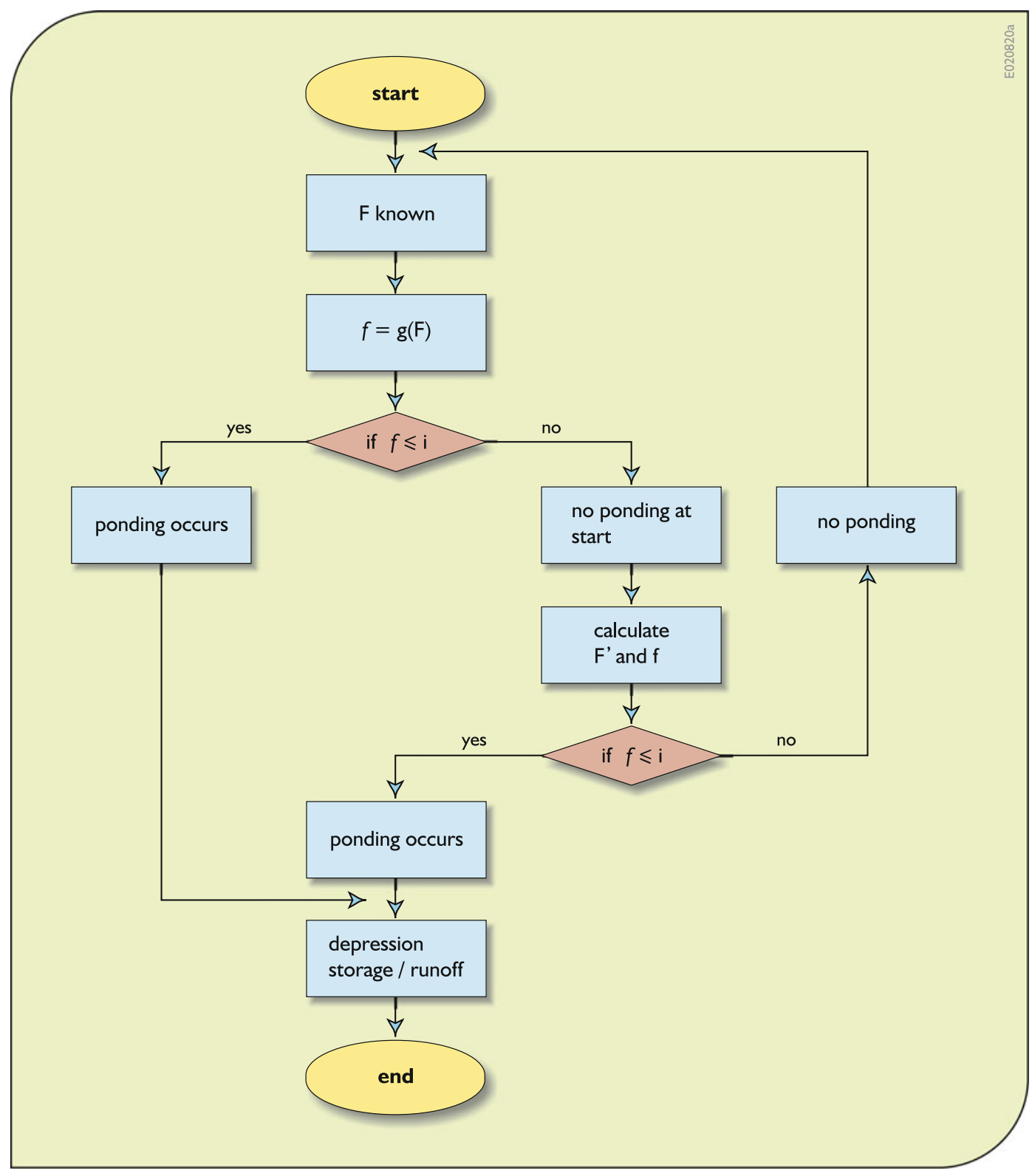

Fig. 12.14 Flow chart of Horton model infiltration algorithm used in each time step of a simulation model 
Table 12.3 Values for Horton's infiltration model for different soil groups as defined by the US Soil Conservation Service

\begin{tabular}{l|ccc|} 
SCS & $\boldsymbol{f}_{\circ}$ & $\begin{array}{l}\boldsymbol{f}_{\mathrm{c}} \\
(\mathrm{mm} / \mathrm{hr})\end{array}$ & $\begin{array}{l}\boldsymbol{k} \\
(1 / \mathrm{mm})\end{array}$ \\
\hline A & 250 & 25.4 & 2 \\
B & 200 & 12.7 & 2 \\
C & 125 & 6.3 & 2 \\
D & 76 & 2.5 & 2 \\
& & & \\
\end{tabular}

\subsubsection{The US Soil Conservation Method (SCS) Model}

The SCS method is a widely used model for predicting runoff from rural catchments, especially in the USA, France, Germany, Australia, and parts of Africa. It has also been used for the permeable component in a semi-urban environment. This runoff model allows for variation in runoff depending on catchment wetness. The model relies on what are called curve numbers, $C N$.

The basis of the method is the continuity equation. The total depth $(\mathrm{mm})$ of rainfall, $R$, either evaporates or is otherwise lost, $I_{\mathrm{a}}$, infiltrates and is retained in the soil, $F$, or runs off the land surface, $Q$

$$
R=I_{\mathrm{a}}+F+Q
$$

The relationship between the depths $(\mathrm{mm})$ of rainfall, $R$, runoff, $Q$, the actual retention, $F$, and the maximum potential retention storage, $S$ (not including $I_{\mathrm{a}}$ ), is assumed to be

$$
F / S=Q /\left(R-I_{\mathrm{a}}\right),
$$

when $R>I_{\mathrm{a}}$. These equations combine to give the SCS model

$$
Q=\left(R-I_{\mathrm{a}}\right)^{2} /\left(R-I_{\mathrm{a}}+S\right)
$$

This model can be modified for use in continuous simulation models.

Numerical representation of the derivative of Eq. 12.29 can be written as Eq. 12.30 for predicting the runoff, $q(\mathrm{~mm} / \Delta t)$, over a time interval $\Delta t$ given the rainfall $r(\mathrm{~mm} / \Delta t)$, in that time interval.

$$
q=r\left(R-I_{\mathrm{a}}\right)\left(R-I_{\mathrm{a}}+2 S\right) /\left(R-I_{\mathrm{a}}+S\right)^{2}
$$

This equation is used incrementally enabling the rainfall and runoff coefficients, $r$ and $q$, to change during the event.

The two parameters $S$ and $I_{\mathrm{a}}$ are assumed to be linearly related by

$$
I_{\mathrm{a}}=k S,
$$

where $0<k<0.2$.

The original SCS approach recommended $k=0.2$. However, other studies suggest that $k$ values between 0.05 and 0.1 may be more appropriate.

The storage variable, $S$, itself is related to an index known as the runoff curve number, $C N$, representing the combined influence of soil type, land management practices, vegetation cover, urban development, and antecedent moisture conditions on hydrological response. $C N$ values vary between 0 and 100, 0 representing no runoff and 100 representing $100 \%$ runoff.

The storage parameter $S$ is related to the curve number $C N$ by

$$
S=(25400 / C N)-254
$$

Curve number values depend on antecedent moisture conditions (AMC) and hydrologic soil 
group. The antecedent moisture conditions are divided into three classes, as defined in Table 12.4.

The four hydrologic soil groups are defined in Table 12.5.

The $C N$ value can either be defined globally for the catchment model or can be associated with specific surface types. $C N$ values for different conditions are available from various sources. Table 12.6 lists some of these relevant to urban areas and antecedent moisture condition class AMC II.

Figure 12.15 identifies the $C N$ values for antecedent moisture content (AMC) classes I and III based on class II values.

Table 12.4 Antecedent moisture classes (AMC) for determining curve numbers $C N$

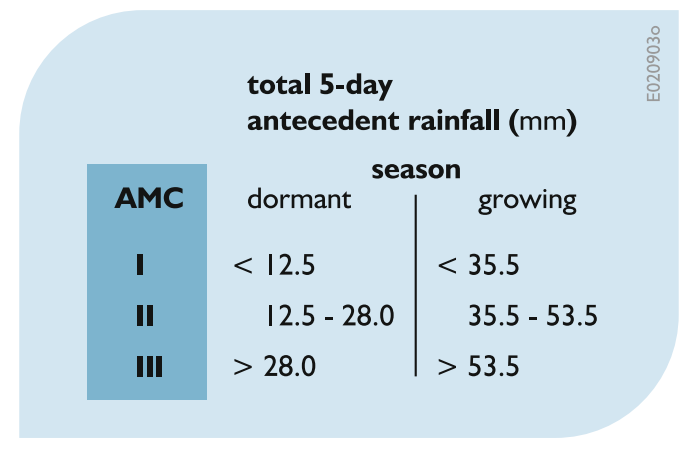

Table 12.5 SCS hydrologic soil groups used in Tables 12.3 and 12.6

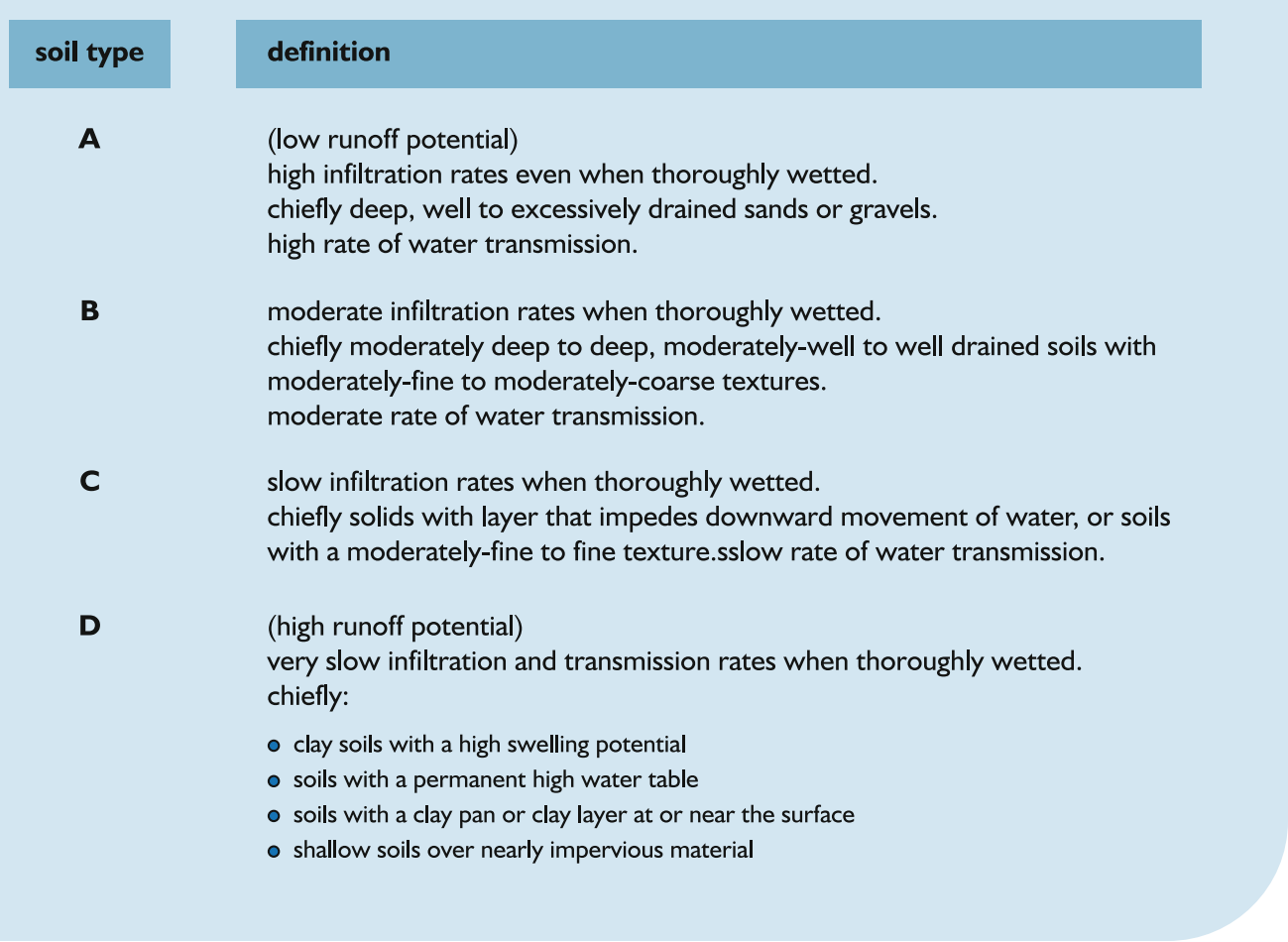


Table 12.6 Initial $C N$ values for AMC II with various urban land use, cover quality, and hydrologic soil groups (defined in Table 12.5)
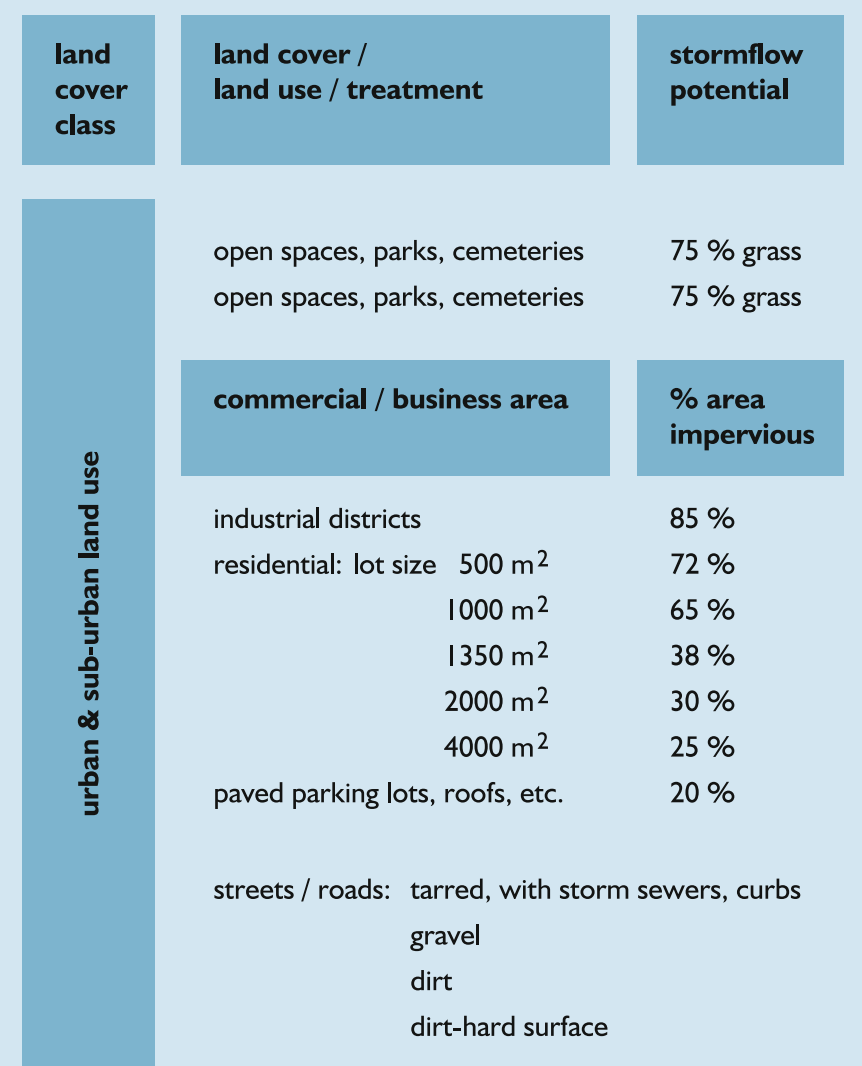

hydrological soil group

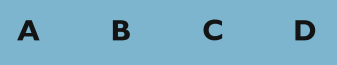

open spaces, parks, cemeteries

open spaces, parks, cemeteries

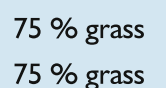

\begin{tabular}{|l|l|l|l|}
\hline 39 & 61 & 74 & 80 \\
\hline 49 & 69 & 79 & 84 \\
\hline
\end{tabular}
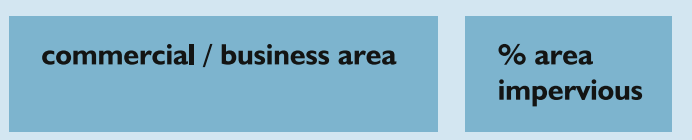

industrial districts
residential: lot size

residential: lot size $500 \mathrm{~m}^{2}$

$$
1000 \mathrm{~m}^{2}
$$

$$
1350 \mathrm{~m}^{2}
$$

$$
2000 \mathrm{~m}^{2}
$$

$$
4000 \mathrm{~m}^{2}
$$

paved parking lots, roofs, etc.

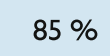

$72 \%$

$65 \%$

$38 \%$

$30 \%$

$25 \%$

$20 \%$

streets / roads: tarred, with storm sewers, curbs

gravel

dirt

dirt-hard surface

\subsubsection{The SWMM Rainfall-Runoff Model}

The rainfall-runoff element of the popular SWMM model generally assumes $100 \%$ runoff from impermeable surfaces and uses Horton or the Green-Ampt model for permeable runoff. The Green-Ampt model is similar to the Horton model, in that it has a conceptual infiltration rate that varies with time. It is therefore applicable to pervious or semipervious catchments (Huber and Dickinson 1988; Roesner et al. 1988).

\subsubsection{Surface Pollutant Loading and Washoff}

The modeling of surface pollutant loading and washoff into sewer systems is very imprecise. Pollutants that build up on the surface of an urban area originate from wind blown dust, debris that is both natural and human-made, including vehicular transport emissions. When rainfall takes place some of this material, as dissolved pollutants and fine solids, is washed 
Fig. 12.15 Runoff curve numbers for AMC classes I and III based on curve numbers for AMC II

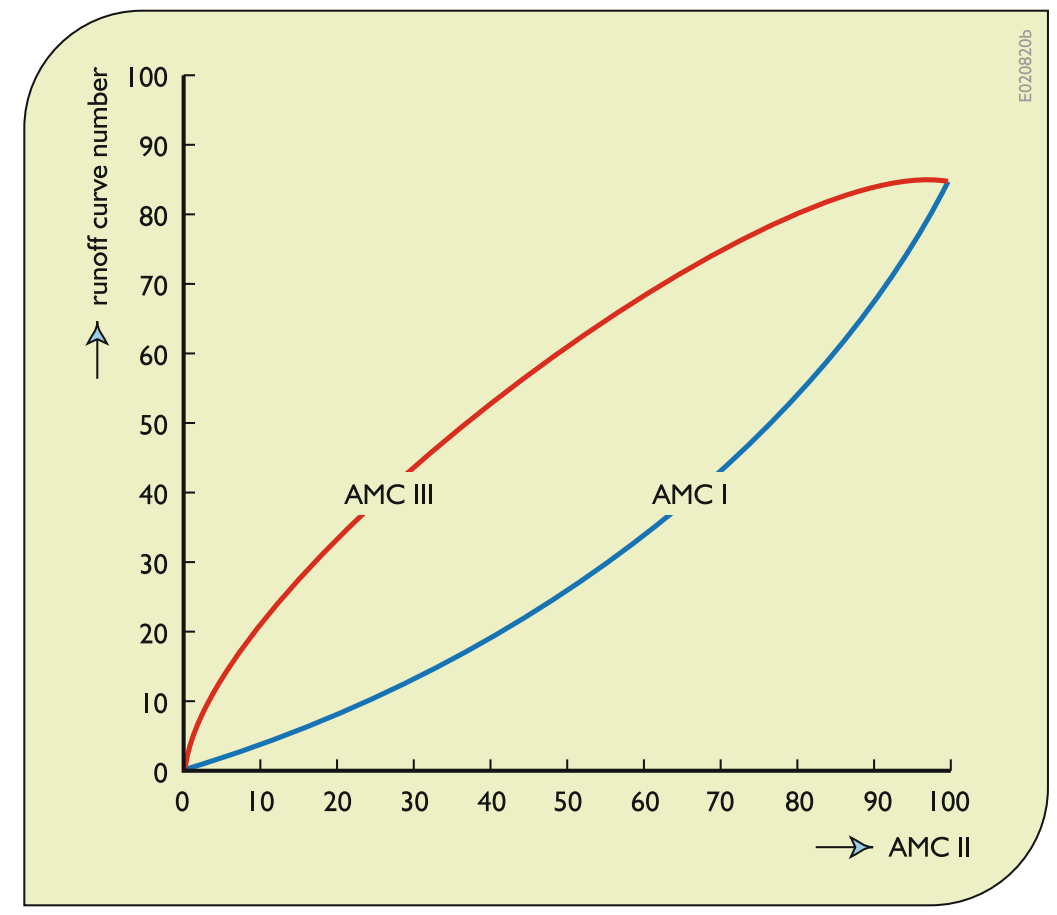

into the stormwater sewers or gullies. During buildup time many of the pollutants degrade.

Deposition of this material is not homogeneous but rather is a function of climate, geography, land use, and human activity. The mechanism of washoff is obviously a function of location, land use, rainfall intensity, slope, flow rate, vehicle disturbance, etc. None of these factors are explicitly modeled in most washoff and sewer flow models.

Measurements made of pollutant accumulation and washoff have been the basis of empirical equations representing both loading and washoff processes. In practice the level of information available and the complexity of the processes being represented make the models of pollutant loading and washoff a tool whose outputs must be viewed for what they are, merely guesses. Modeling does not change this, it only has the potential of making those guesses better.

\subsubsection{Surface Loading}

Pollutant loadings and accumulation on the surface of an urban catchment occur during dry periods between rainstorms.
A common hypothesis for pollutant accumulation during dry periods is that the mass loading rate, $m_{\mathrm{P}},(\mathrm{kg} / \mathrm{ha} /$ day $)$ of pollutant $P$ is constant. This assumed constant loading rate on the surface of the ground can vary over space and is related to the land use of that catchment. In reality these loadings on the land surface will not be the same, neither over space nor over time. Hence to be more statistically precise, a time series of loadings may be created from one or more probability distributions of observed loadings. (Just how this may be done is discussed in Chaps. 6 and 7.) Different probability distributions may apply when, for example, weekend loadings differ from workday loadings. However, given all the other uncertain assumptions in any urban loading and washoff model, the effort may not be justified.

As masses of pollutants accumulate over a dry period they may degrade as well. The time rate of degradation of a pollutant $P$ is commonly assumed to be proportional to its total accumulated mass $M_{\mathrm{P}}(\mathrm{kg} / \mathrm{ha})$. Assuming a proportionality constant (decay rate constant) of $k_{\mathrm{P}}$ (1/day), the rate of change in the accumulated mass $M_{\mathrm{P}}$ over time $t$ is 


$$
\mathrm{d} M_{\mathrm{P}} / \mathrm{d} t=m_{\mathrm{P}}-k_{\mathrm{P}} M_{\mathrm{P}}
$$

As the number of days during the dry period gets very large the limiting accumulation of a mass $M_{\mathrm{P}}$ of pollutant $P$ is $m_{\mathrm{P}} / \mathrm{k}_{\mathrm{P}}$. If there is no decay, then of course $k_{\mathrm{P}}$ is 0 and the limiting accumulation is infinite.

Integrating Eq. 12.33 over the duration $\Delta t$ (days) of a dry period yields the mass, $M_{\mathrm{P}}(\Delta t)$ $(\mathrm{kg} / \mathrm{ha})$ of each pollutant available for washoff at the beginning of a rainstorm.

$$
M_{\mathrm{P}}(\Delta t)=M_{\mathrm{P}}(0) \mathrm{e}^{-k \mathrm{p} \Delta t}+\left[m_{\mathrm{P}}\left(1-\mathrm{e}^{-k \mathrm{p} \Delta t}\right) / k_{\mathrm{P}}\right]
$$

where $M_{\mathrm{P}}(0)$ is the initial mass of pollutant $P$ on the catchment surface at the beginning of the dry period, i.e., at the end of the previous rainstorm.

Sediments (that become suspended solids in the runoff) are among the pollutants accumulating on the surface of urban catchments. They are important by themselves, but also because some of the other pollutants that accumulate become attached to these sediments. Sediments are typically defined by their medium diameter size value $\left(d_{50}\right)$. Normally a minimum of two sediment fractions are modeled, one coarse high-density material (grit) and one fine (organics).
The sediments of each diameter size class are commonly assumed to have a fixed amount of pollutants attached to them. The fraction of each attached pollutant, sometimes referred to as the potency factor of the pollutant, is expressed as $\mathrm{kg}$ of pollutant per $\mathrm{kg}$ of sediment. Potency factors are one method for defining pollutant inputs into the system.

\subsubsection{Surface Washoff}

Pollutants in the washoff can be dissolved in water, or they can be attached to the sediments. Many models of the transport of dissolved and particulate pollutants through a sewerage system assume each pollutant is conservative-it does not degrade with time. For practical purposes this is a reasonable assumption when the time of flow in the sewers is relative short. Otherwise it may not be a good assumption, but at least it is a conservative one.

Pollutants can enter the sewer system from a number of sources. A major source is the washoff of pollutants from the catchment surface during a rainfall event. Their removal is caused by the impact of rainfall and by erosion from runoff flowing across the surface. Figure 12.16 shows schematically some sources of pollution in the washoff model.

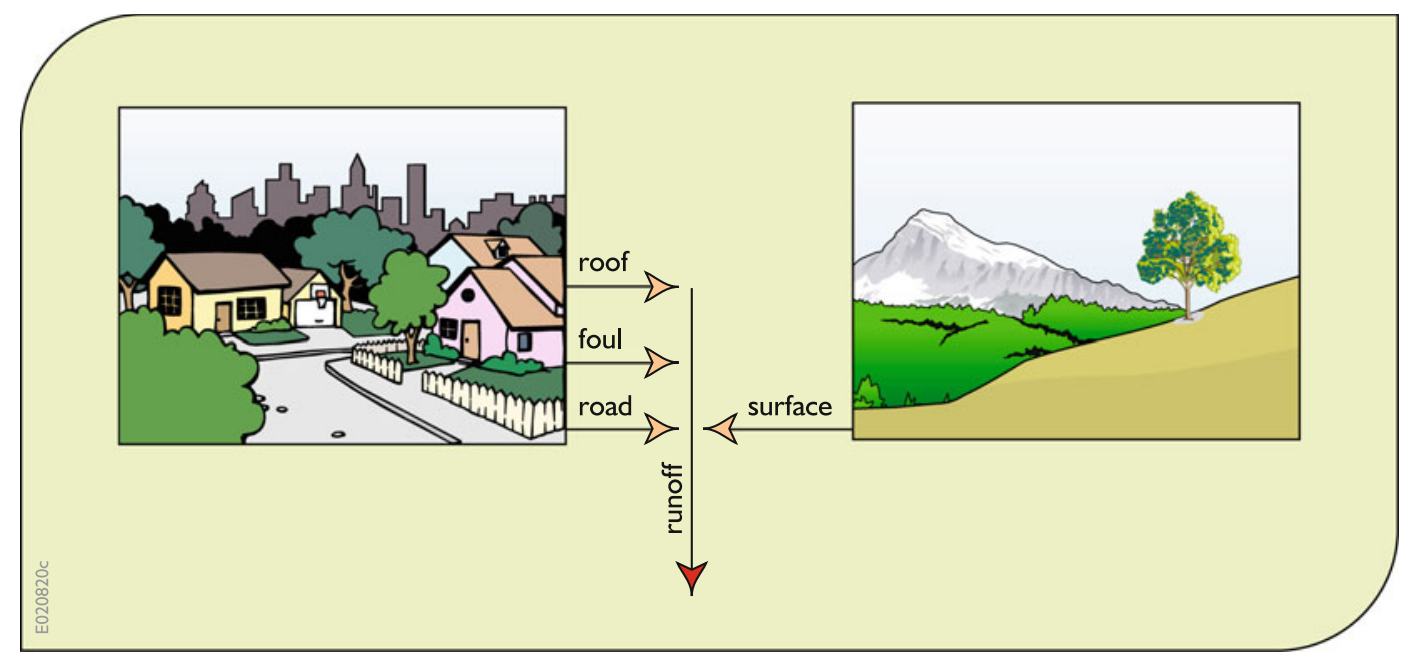

Fig. 12.16 Some sources of pollutants in the washoff to sewer systems from land surfaces 
The rate of pollutant washoff is dependent on an erosion coefficient, $\alpha_{\mathrm{P}}$, and the quantity, $M_{\mathrm{P}}$, of available pollutant, $P$. As the storm event proceeds and pollutants are removed from the catchment, the quantities of available pollutants decrease, hence the rate of pollutant washoff decreases even with the same runoff.

When runoff occurs, a fraction of the accumulated load may be contained in that runoff. This fraction will depend on the extent of runoff. If a part of the surface loading of a pollutant is attached to sediments, its runoff will depend on the amount of sediment runoff, which in turn is dependent on the amount of surface water runoff.

The fraction of total surface loading mass contained in the runoff will depend on the runoff intensity. The following approximate relation may apply for the fraction, $f_{t}^{R}$, of pollutant $P$ in the runoff $R_{t}$ in period $t$ :

$$
f_{\mathrm{t}}^{\mathrm{P}}=\alpha_{\mathrm{P}} R_{\mathrm{t}} /\left(1+\alpha_{\mathrm{P}} R_{\mathrm{t}}\right)
$$

The greater the runoff $R_{t}$ the greater will be the fraction $f_{t}^{P}$ of the total remaining pollutant loading in that runoff. The values of the parameters $\alpha_{P}$ are indicators of the effectiveness of the runoff in picking up and transporting the particular pollutant mass. Their values are dependent on the type of pollutant $P$ and on the land cover and topography of particular basin or drainage area. They can be determined based on measured pollutant mass surface loadings and on the mass of pollutants contained in the rainfall and sediment runoff, preferably at the basin of interest. Since such data are difficult, or at least expensive, to obtain, they usually are based on experiments in laboratories.

A mass balance of pollutant loadings can define the total accumulated load, $M_{\mathrm{Pt}+1}$ at the end of each simulation time period $t$ or equivalently at the beginning of each time period $t+1$. Assuming a daily simulation time step,

$$
M_{\mathrm{Pt}+1}=\left(1-f_{\mathrm{t}}^{\mathrm{P}}\right) M_{\mathrm{Pt}} \mathrm{e}^{-\mathrm{kP}}+m_{\mathrm{P}}
$$

Of interest, of course, is the total pollutant mass in the runoff. For each pollutant type $P$ in each period $t$ these will be $f_{\mathrm{t}}^{\mathrm{P}}\left(M_{\mathrm{Pt}}\right)$ for the dissolved part. The total mass of pollutant $P$ in the runoff must also include those attached fractions (potency factors), if any, of each sediment size class being modeled as well.

As the sediments are routed through the system those from different sources are mixed together. The concentrations of associated pollutants therefore change during the simulation as different proportions of sediment from different sources are mixed together. The results are given as concentrations of sediment, concentrations of dissolved pollutants, and concentrations of pollutants associated with each sediment fraction.

\subsubsection{Stormwater Sewer and Pipe Flow}

Flows in pipes and sewers have been analyzed extensively and their representation in models is generally accurately defined. The hydraulic characteristics of sewage are essentially the same as clean water. Time-dependent effects are, in part, a function of the change in storage in manholes. Difficulties in obtaining convergence occurs at pipes with steep to flat transitions, dry pipes, etc., and therefore additional features and checks are needed to achieve satisfactory model results.

\subsubsection{Sediment Transport}

Pollutant transport modeling of both sediment and dissolved fractions involves defining the processes of erosion and deposition and advection and possibly dispersion. One-dimensional models by their very nature cannot predict the sediment gradient in the water column. In addition the concept of the sewer being a bioreactor is not included in most simulation models. Most models assume pollutants are conservative during the time in residence in the drainage system before being discharged into a water body. All these processes that take place in transient are generally either ignored or approximated using a range of assumptions.

\subsubsection{Structures and Special Flow Characteristics}

Manholes, valves, pipes, pumping stations, overflow weirs, etc., that impact the flows and 
head losses in sewers can be explicitly included in deterministic simulation models. The impact of some of these structures can only be predicted using 2- or 3-dimensional models. However, the ever-increasing power of computers is making higher dimensional fluid dynamic analyses increasingly available to practicing engineers. The biggest limitation may be more related to data and calibration than to computer models and costs.

\subsubsection{Water Quality Impacts}

\subsubsection{Slime}

Slime can build up on the perimeter of sewers that contain domestic sewage. The buildup of slime may have a significant effect on roughness. In a combined system the effect will be less as the maximum daily flow of domestic sewage will not usually be a significant part of pipe capacity.

The extent to which the roughness is increased by sliming depends on the relation between the sewage discharge and the pipe-full capacity. Sliming will occur over the whole of the perimeter below the water level that corresponds to the maximum daily flow. The slime growth will be heaviest in the region of the maximum water level. Over the lower part of the perimeter, the surface will still be slimed, but to a lesser extent than at the waterline. Above the maximum waterline the sewer surface will tend to be fairly free of slime.

\subsubsection{Sediment}

When sediment is present in the sewer the roughness increases quite significantly. It is difficult to relate the roughness to the nature and time history of the sediment deposits. Most stormwater sewers contain some sediment deposits, even if only temporarily. The only data available suggest that the increase in head loss can range from 30 to $300 \mathrm{~mm}$, depending on the configuration of the deposit and on the flow conditions. The higher roughness value is more appropriate when the sewer is flowing part full and when considerable energy is lost as a result of the generation of surface disturbances. In practice the lower roughness values are used as flow states of interest are usually extreme events and therefore sewers are operating in surcharge.

\subsubsection{Pollution Impact on the Environment}

The effects of combined sewer outflows (CSOs) or discharges are particularly difficult to quantify and regulate because of their intermittent and varied nature. Their immediate impact can only be measured during a spill event, and their chronic effects are often difficult to isolate from other pollution inputs. Yet CSOs are one of the major causes of poor river water quality. Standards and performance criteria specifically for intermittent discharges are therefore needed to reduce the pollutants in CSOs.

Drainage discharges that affect water quality include:

(1) oxygen-demanding substances. These can be either organic, such as fecal matter, or inorganic. (Heated discharges, such as cooling waters, reduce the saturated concentration of dissolved oxygen),

(2) substances that physically hinder reoxygenation at the water surface, such as oils,

(3) discharges containing toxic compounds, including ammonia, pesticides, and some industrial effluents, and

(4) discharges that are high in suspended solids and thus inhibit biological activity by excluding light from water or by blanketing the bed.

Problems arise when pollutant loads exceed the self-purification capacity of the receiving water, harming aquatic life, and restricting the use of the water for consumption and many industrial and recreational purposes. The assimilative capacity for many toxic substances is very low. Water polluted by drainage discharges can create nuisances such as unpleasant odors. It can also be a direct hazard to health, particularly in tropical regions where waterborne diseases such as cholera and typhoid prevail.

The aim of good drainage design, with respect to pollution, is to balance the effects of 
continuous and intermittent discharges against the assimilation capacity of the water, so as to achieve in a cost and socially effective way the desired quality of the receiving water.

Figure 12.17 shows the effect of a discharge that contains suspended solids and organic matter. The important indicators showing the effect of the discharge are the dissolved oxygen in diagram "a" and the clean water fauna shown in diagram " $d$ ". The closeness with which the clean water fauna follow the dissolved oxygen reflects the reliance of a diverse fauna population on dissolved oxygen. These relationships are used by biologists to argue for greater emphasis on biological indicators of pollution as they respond to intermittent discharges better than chemical tests which, if not continuous, may miss the pollution incident. There are a number of biological indexes in use in most countries in Europe.

In Fig. 12.17 the $B O D$ in diagram "a" rises or stays constant after release despite some of the

(a)

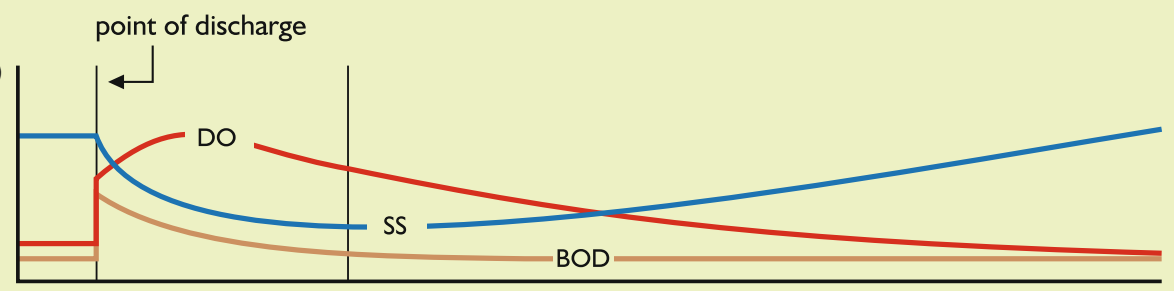

(b)

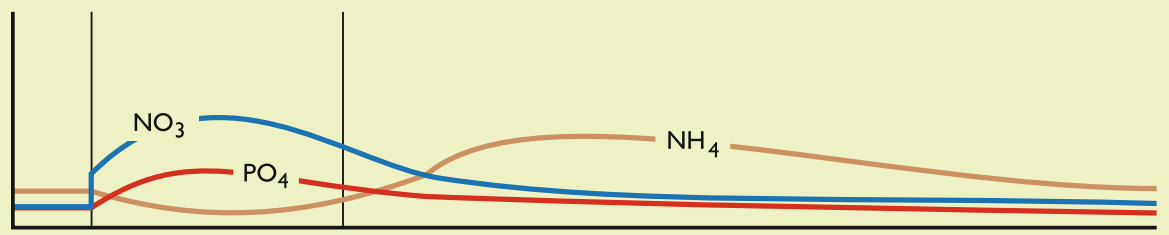

(c)

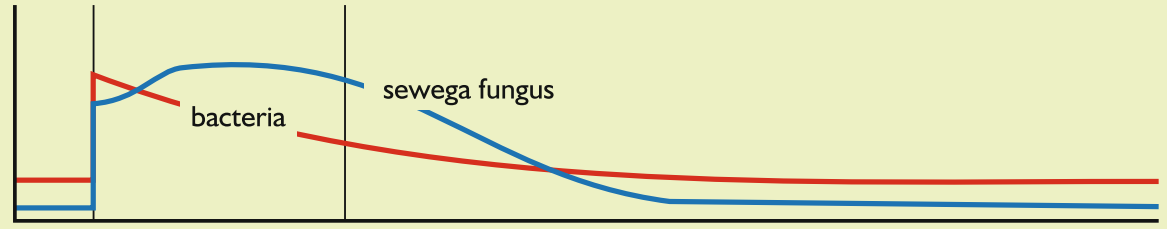

(d)

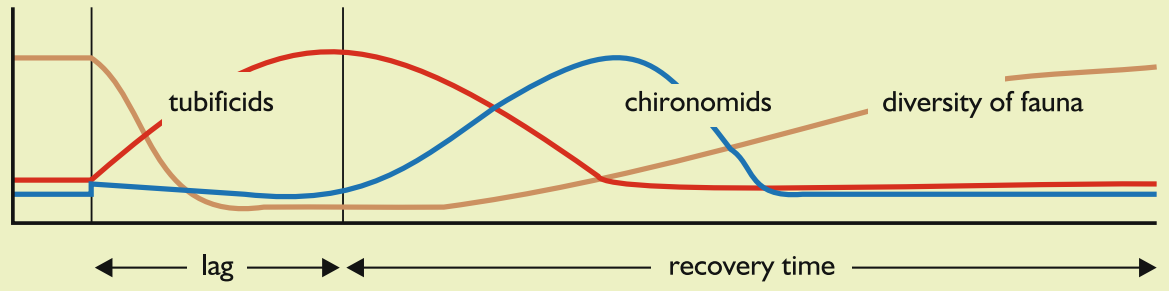

Fig. 12.17 Pollution impact along a waterway downstream from its discharge 
pollutant being digested and depleting the dissolved oxygen. This is because there is a time lag of up to several days while the bacteria, which digest the pollutant, multiply. The suspended solids (SS) settle relatively quickly and they can then be a source of pollutants if the bed is disturbed by high flows. This can create a subsequent pollution incident especially if the suspended solids contain quantities of toxic heavy metals.

Diagram "b" of Fig. 12.17 shows ammonium ions $\left(\mathrm{NH}_{4}{ }^{+}\right)$that are discharged as part of the dissolved pollutants being oxidized to nitrates $\left(\mathrm{NO}_{3}{ }^{-}\right)$. The rise in the ammonium concentration downstream of the discharge is relevant due to the very low tolerance many aquatic organisms, particularly fish, have to the chemical. The ammonium concentration rises if the conditions are anaerobic and will then decline once aerobic conditions return and the ammonium ions are oxidized to nitrates.

Diagrams "c" and " $d$ " show the effect of combined sewer overflows (CSOs) on flora and fauna. The increased quantities of phosphate and nitrate nutrients that they consume can lead to eutrophication. The fauna show perhaps the clearest pattern of response. The predictability of this response has lead to the development of the many biological indices of pollution. The rapid succession of organisms illustrates the pattern of dominance of only a few species in polluted conditions. For example, tubificid worms can exist in near anaerobic conditions, and having few competitors, they can multiply prolifically. As the oxygen levels increase these organisms are succeeded by Chironomids (midge larvae) and so on until in clean well-oxygenated water, there is a wide diversity of species all competing with each other.

In most circumstances, the concentration of dissolved oxygen $(D O)$ is the best indicator of the "health" of a water source. A clean water source with little or no biodegradable pollutants will have an oxygen concentration of about 9$10 \mathrm{mg} / \mathrm{l}$ when in equilibrium with air in a temperate environment. This maximum saturation concentration is temperature dependent. The hotter the water is the lower the $D O$ saturation concentration.

All higher forms of life in a river require oxygen. In the absence of toxic impurities there is a close correlation between $D O$ and biodiversity. For example, most game fish die when the $D O$ concentration falls below about $4 \mathrm{mg} / \mathrm{l}$.

Perhaps of more pragmatic significance is the fact that oxygen is needed in the many natural treatment processes performed by microorganisms that live in natural water bodies. The quantity of oxygen required by these organisms to breakdown a given quantity of organic waste is, as previously discussed, the biochemical oxygen demand $(B O D)$. It is expressed as $\mathrm{mg}$ of dissolved oxygen required by organisms to digest and stabilize the waste in a liter of water. These organisms take time to fully digest and stabilize the waste. The rate at which they do so depends on the temperature of, and the quantity of these organisms available in, the water at the start.

Since the $B O D$ test measures only the biodegradable material it may not give an accurate assessment of the total quantity of oxidizable material in a sample in all circumstances (e.g., in the presence of substances toxic to the oxidizing bacteria). In addition, measuring the $B O D$ of a sample of water typically takes a minimum of 5 days. The chemical oxygen demand (COD) test is a quicker method and measures the total oxygen demand. It is a measure of the total amount of oxygen required to stabilize all the waste. While the value of $C O D$ is never less than the value of $B O D$, it is the faster reacting $B O D$ that impacts water quality. And this is what most people care about. However, determining a relationship between $B O D$ and $C O D$ at any site can provide guideline values for $B O D$ based on $C O D$ values.

Tables 12.7 and 12.8 provide some general ranges of pollutant concentrations in CSOs from urban catchments.

Water quality models for urban drainage are similar, or simpler versions of water quality models for other water bodies (as discussed in 
Table 12.7 Typical quality of domestic sewage

\begin{tabular}{|c|c|c|c|}
\hline constituent & raw & treated & overflow \\
\hline $\begin{array}{l}\text { suspended } \\
\text { solids } \mathrm{mg} / \mathrm{l}\end{array}$ & 300 & 5 & 200 \\
\hline BOD mg/l & 367 & 10 & 300 \\
\hline $\begin{array}{l}\text { COD } \\
\mathrm{mg} / \mathrm{l}\end{array}$ & 470 & 15 & 350 \\
\hline $\begin{array}{l}\text { ammonia } \\
\mathrm{mg} / \mathrm{l}\end{array}$ & 39 & 7 & 30 \\
\hline
\end{tabular}

Table 12.8 Pollutant concentrations $(\mathrm{mg} / \mathrm{l})$ in urban runoff

\begin{tabular}{|c|c|c|c|c|}
\hline constituent & $\begin{array}{l}\text { highway } \\
\text { runoff }\end{array}$ & $\begin{array}{l}\text { residential } \\
\text { area }\end{array}$ & $\begin{array}{l}\text { commercial } \\
\text { area }\end{array}$ & $\begin{array}{l}\text { industrial } \\
\text { area }\end{array}$ \\
\hline $\begin{array}{l}\text { suspended } \\
\text { solids } \mathrm{mg} / \mathrm{I}\end{array}$ & $28-1178$ & $112-1104$ & $230-1894$ & $34-374$ \\
\hline BOD5 mg/l & $12-32$ & $7-56$ & $5-17$ & $8-12$ \\
\hline $\begin{array}{l}\text { COD } \\
\mathrm{mg} / \mathrm{l}\end{array}$ & $|28-17|$ & $37-120$ & $74-160$ & $40-70$ \\
\hline $\begin{array}{l}\text { ammonia } \\
\mathrm{mg} / \mathrm{l}\end{array}$ & $0.02-2.1$ & $0.3-3.3$ & $0.03-5.1$ & $0.2-1.2$ \\
\hline lead mg/l & $0.15-2.9$ & $0.09-0.44$ & $0.1-0.4$ & $0.6-1.2$ \\
\hline
\end{tabular}


Chap. 10). Often just a simple mixing and dilution model will be sufficient to predict the concentration of pollutants at any point in a sewer system. For example, such models may be sufficient for some toxic substances that are not broken down. Once the flows in the CSO enter the receiving water body, models discussed in Chap. 10 can be used to estimate their fate as they travel with the water in the receiving water body.

A factor that makes predicting the impacts of overflow discharges particularly difficult is the noncontinuous nature of the discharges and their pollutant concentrations. In the first sanitary or foul flush the fine sediments deposited in the pipes during dry periods are swept up and washed out of the system. Most existing models, termed constant concentration models, do not account for this phenomenon. Since many of the most significant pollution events occur when the river has low flows, and hence low dilution factors, the quantity of spill in the first flush may be very important in the overall pollution impact.

\subsubsection{Bacteriological and Pathogenic Factors}

The modeling of pathogenic microorganisms is particularly difficult since there are a very large number of pathogenic organisms, each usually with a unique testing procedure, many of which are expensive. Also many pathogens may present a significant risk to human health in very small numbers. Incubation periods of over $24 \mathrm{~h}$ are not uncommon and there are as yet no automatic real-time monitoring techniques in commercial use.

The detection of pathogens relies heavily on indicator organisms that are present in feces in far higher numbers than the pathogenic organisms. Escherichia Coliform (E. coli) bacteria is the most common fecal indicator. This indicator is commonly used throughout the world to test water samples for fecal contamination.

Because of the problems in measuring microbiological parameters involved in CSOs, most sophisticated methods of determining the quality of sewer water restrict themselves to more easily measured determinants such as $B O D$,
$C O D$, suspended solids, ammonia, nitrates, and similar constituents.

\subsubsection{Oil and Toxic Contaminants}

Oils are typically discharged into sewers by people, industries, or are picked up in the runoff from roads and road accidents. Since oil floats on water surfaces and disperses rapidly into a thin layer, a small quantity of oil discharged into a water body can prevent reoxygenation at the surface and thus suffocate the organisms living there. The dispersal rate changes with oil viscosity and the length of time the oil is a problem will partly depend on the surface area of the receiving water as well.

There are three main sources of toxic contaminants that may be discharged from CSOs:

- Industrial effluents. These could be anything from heavy metals to herbicides.

- Surface washoff contaminants. These may be contaminants washed off the surface in heavy rainstorms that in agricultural and suburban residential areas will probably include pesticides and herbicides. In many cases these contaminants make a larger contribution to the pollutant load than the domestic sanitary flow.

- Substances produced naturally in the sewer. Various poisonous gases are produced in sewers. From the point of view of water quality, ammonia is almost certainly the most important though nitrogen sulfide can also be significant.

\subsubsection{Suspended Solids}

Discharges high in suspended solids pose a number of problems. They almost invariably exert an oxygen demand. If they remain in suspension they can prevent light from penetrating the water and thus inhibit photosynthesis. If deposited they become a reservoir of oxygen demanding particles that can form an anaerobic layer on the bed, decreasing biodiversity. They also can degrade the bed for fish (such as salmon) spawning. If these suspended solids contain toxic substances, such as heavy metals, the problems can be more severe and complex. 


\subsubsection{Green Urban Infrastructure}

Many urban areas are being recognized for successfully using natural ecosystems to reduce the costs of providing clean drinking water and managing stormwater. Moreover, this "green" infrastructure provides many quality-of-life benefits, by improving air quality, increasing shading, contributing to higher property values, and enhancing streetscapes. New York City in the US, for example, estimates that such efforts have saved ratepayers billions of dollars - by eliminating the need for construction of hard "gray" infrastructure such as storm sewers and filtration plants - while preserving large tracts of natural areas. The department's Green Infrastructure Plan lays out how the city will improve the water quality in New York Harbor by capturing and retaining stormwater runoff before it enters the sewer system using streetside swales, tree pits, and blue and green rooftop detention techniques to absorb and retain stormwater (Fig. 12.18). This hybrid approach reduces combined sewer overflows by 12 billion gallons a year-over 2 billion gallons a year more than the current all-gray strategy-while saving New Yorkers \$2.4 billion (NYCDEP 2012).

\subsection{Urban Water System Modeling}

Optimization and simulation models are becoming increasingly available and used to analyze a variety of design and operation problems involving urban water systems. Many are incorporated within graphics user interfaces that facilitate the use of the models and the understanding and further analyses of their results.

\subsubsection{Optimization}

Methods for finding optimal solutions are becoming increasingly effective in the design and planning of urban infrastructure. Yet they are challenged by the complexity and nonlinearity of especially urban water distribution networks.
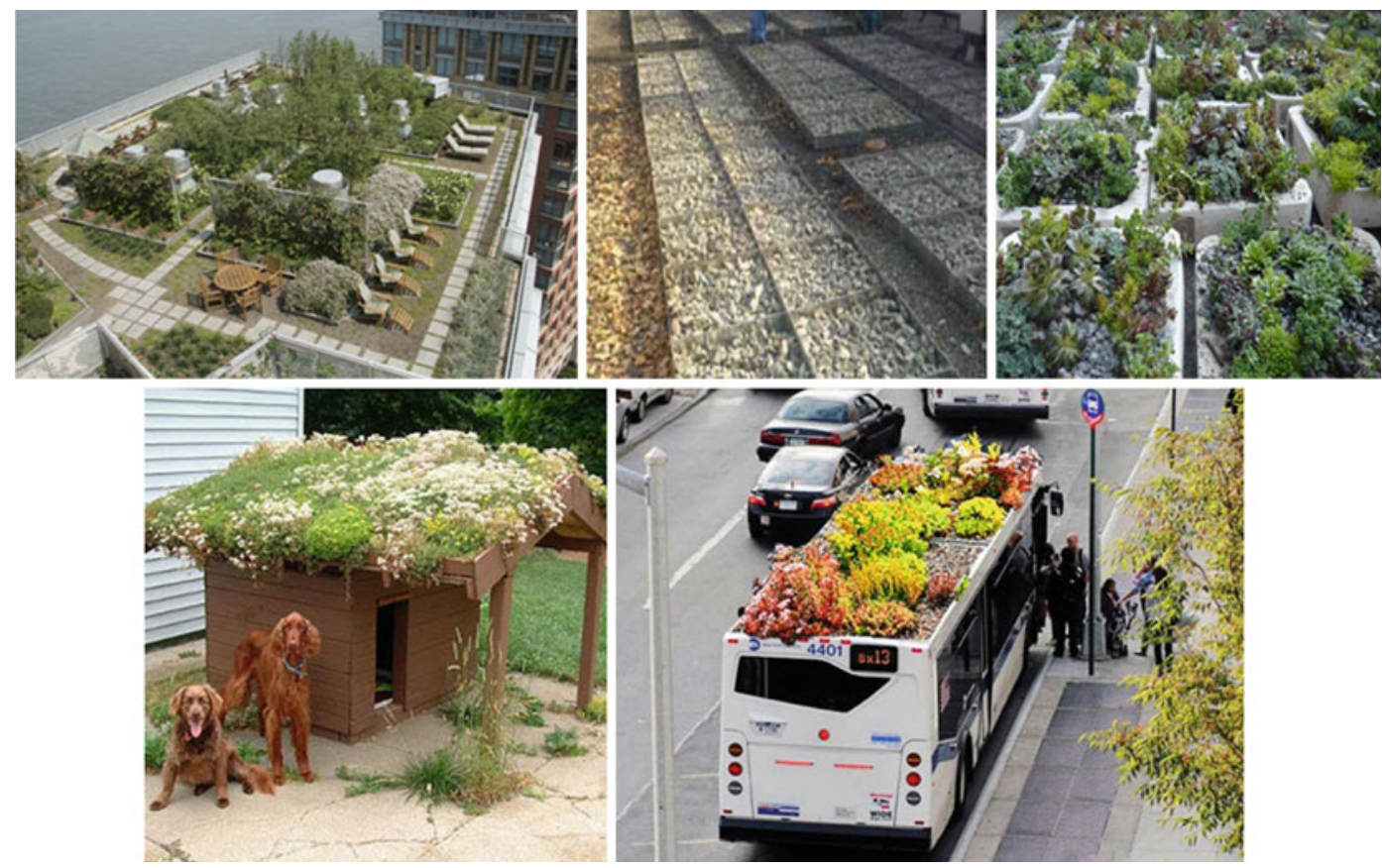

Fig. 12.18 Examples of "green" and "blue" (upper center) rooftop infrastructures for reducing urban storm runoff and at the same time enhancing the attractiveness of the urban environment. Some go to extremes 
Numerous calibration procedures for water distribution system models have been developed since the 1970s. Trial and error approaches (Rahal et al. 1980; Walski 1983) were replaced with explicit type models (Ormsbee et al. 1986; Boulos et al. 1990). More recently, calibration problems have been formulated and solved as optimization problems. Most of the approaches used so far are either local or global search methods. Local search gradient methods have been used by Shamir (1974), Lansey et al. (1991), Datta et al. (1994), Reddy et al. (1996), Pudar et al. (1992), and Liggett et al. (1994) to solve various steady-state and transient model calibration problems (Datta et al. 1994; Savic et al. 1995; Greco et al. 1999; Vitkovsky et al. 2000).

Evolutionary search algorithms, discussed in Chap. 5, are now commonly used for the design and calibration of various highly nonlinear hydraulic models of urban systems. They are particularly suited for search in large and complex decision spaces (e.g., in water treatment, storage and distribution networks). They do not need complex mathematical matrix inversion methods and they permit easy incorporation of additional calibration parameters and constraints into the optimization process (Savic et al. 1995; Vitkovsky and Simpson 1997; Tucciarelli et al. 1999; Vitkovsky et al. 2000).

In addition to calibration, these evolutionary search methods have been used extensively to find least-cost designs of water distribution systems (Simpson et al. 1994; Dandy et al. 1996; Savic and Walters 1997). Other applications include the development of optimal replacement strategies for water mains (Dandy and Engelhardt 2001), finding the least expensive locations of water quality monitoring stations (Al-Zahrani and Moied 2001), minimizing the cost of operating water distribution systems (Simpson et al. 1999), and identifying the least-cost development sequence of new water sources (Dandy and Connarty 1995).

These search methods are also finding a role in developing master or capital improvement plans for water authorities (Murphy et al. 1996; Savic et al. 2000). In this role they have shown their ability to identify low cost solutions for highly complex water distribution systems subject to a number of loading conditions and a large number of constraints. Constraints on the system include maximum and minimum pressures, maximum velocities in pipes, tank refill conditions, and maximum and minimum tank levels.

As part of any planning process, water authorities need to schedule the capital improvements to their system over a specified planning period. These capital improvements could include water treatment plant upgrades, new water sources as well as new, duplicate or replacement pipes, tanks, pumps, and valves. This scheduling process requires estimates of how water demands are likely to grow over time in various parts of the system. The output of a scheduling exercise is a plan that identifies what facilities should be built, installed, or replaced, to what capacity and when, over the planning horizon.

The application of optimization to master planning for complex urban water infrastructure presents a significant challenge. Using optimization methods to find the minimum cost design of a system of several thousand pipes for a single demand at a single point in time is difficult enough on its own. The development of least-cost system designs over a number of time periods experiencing multiple increasing demands can be much more challenging.

Consider, for example, developing a master plan for the next 20 years divided into four 5 -year construction periods. The obvious way to model this problem is to include the system design variables for each of the next four 5-year periods given the expected demands at those times. The objective function for this optimization model might be to minimize the present value of all construction, operation, and maintenance costs.

Dandy et al. (2002) have developed and applied two alternative modeling approaches. One approach is to find the optimal solution for the system for only the final or "target" year. The solution to this first optimization problem identifies those facilities that will need to be constructed sometime during the 20-year planning period. A series of subproblems are then optimized, one for each intermediate planning stage, 
to identify when each facility that is to be built should be built. For these subproblems, the decisions are either to build or not to build to a predetermined capacity. If a component is to be built, its capacity has already been determined in the target year optimization.

For the second planning stage, all options selected in the first planning stage are locked in place and a choice is made from among the remaining options. Therefore, the search space is smaller for this case. A similar situation applies for the third planning stage.

An alternative approach is to solve the first optimization problem for just the first planning stage. All options and all sizes are available. The decisions chosen at this time are then fixed, and all options are considered in the next planning stage. These options include duplication of previously selected facilities. This pattern is repeated until the final "target" year is reached.

Each method has its advantages and disadvantages. For the first "Build-to-Target" method, the optimum solution is found for the "target year". This is not necessarily the case for the "Build-up" method. On the other hand, the latter buildup method finds the optimal solution for the first planning stage that the "Build-to-Target" method does not necessarily do. As the demands in the first planning stage are known more precisely than those for the "target" year, this may be an advantage.

The buildup method allows small pipes to be placed at some locations in the first time planning stage, if warranted, and these can be duplicated at a later time; the build-to-target method does not. This allows greater flexibility, but may produce a solution that has a higher cost in present value terms.

The results obtained by these or any other optimization methods will depend on the assumed growth rate in demand, the durations of the planning intervals, the economic discount rate if present value of costs is being minimized, and the physical configuration of the system under consideration. Therefore, the use of both methods is recommended. Their outputs, together with engineering judgment, can be the basis of developing an adaptive master development plan. Remember, it is only the current construction period's solution that should be of interest. Prior to the end of that period the planning exercise with updated information can be performed again to obtain a better estimate of what the next period's decisions should be.

\subsubsection{Simulation}

Dynamic simulation models are increasingly replacing steady-state models for analyzing water quantity, pressure and water quality in distribution and collection networks. Dynamic models provide estimates of the time-variant behavior of water flows and their contaminants in distribution networks, even arising from flow reversals. The use of long time-series analysis provides a continuous representation of the variability of flow, pressure, and quality variables throughout the system. It also facilitates the understanding of transient operational conditions that may influence, for example, the way contaminants are transported within the network. Dynamic simulation also lends itself well to statistical analyses of exposure. This methodology is practical for researchers and practitioners using readily available hardware and software (Harding and Walski 2002).

Models used to simulate a sequence of time periods must be capable of simulating systems that operate under highly variable conditions. Urban water systems are driven by water use and rainfall, which by its nature is stochastic. Changes in water use, control responses and dispatch of sources, and random storms over different parts of the catchment all can affect flow quantities, the flow direction and thus the spatial distribution of contaminants. Because different water sources often have different quality, changing water sources can cause changes in the quality of water within the system (see Box 12.1).

The simulation of water quantities and qualities in urban catchments serve three general purposes:

- Planning/Design-These studies define system configurations, size or locate facilities, or define long-term operating policies. They adopt a long-term perspective but, under 
current practices, use short, hypothetical scenarios based on representative operating conditions. In principle, the statistical distribution of system conditions should be an important consideration, but in practice variability is considered only by analyses intended to represent worst-case conditions.

- Operations-These short-term studies analyze scenarios that are expected to occur in the immediate future so as to inform immediate operational decisions. These are based on current system conditions and expected operating conditions. These analyses are often driven by regulations.

- Forensics-These studies are used to link presence of contaminants to the risk or actual occurrence of disease. Depending on whether the objective is cast in terms of acute or chronic exposures, such studies may adopt short- or long-term perspectives. Because there are often dose/response relationships and issues of latency in the etiology of disease, explicit consideration of the spatial distribution, timing, frequency, duration and level of contamination is important to these studies (Rodenbeck and Maslia 1998; Aral et al. 1996; Webler and Brown 1993).

\subsection{Conclusions}

Urban water systems must include not only the reservoirs, groundwater wells, and aqueducts that are the sources of water supplies needed to meet the varied demands in an urban area, but also the water treatment plants, the water distribution systems that transport that water, together with the pressures required, to where the demands are located. Once water is used, the now wastewater needs to be collected and transported to where it can be treated and either reused or discharged back into the environment. Overlaying all of this hydraulic infrastructure and plumbing is the urban stormwater drainage system.

Well-designed and operated urban water systems are critically important for maintaining public health as well as for controlling the quality of the waters into which urban runoff is discharged. In most urban areas in developed regions, government regulations require designers and operators of urban water systems to meet three sets of standards. Pressures must be adequate for fire protection, water quality must be adequate to protect public health, and urban drainage of waste and stormwaters must meet effluent and receiving water body quality standards. This requires monitoring as well as the use of various models for detecting leaks and for predicting the impacts of alternative urban water treatment, distribution, and collection system designs and operating, maintenance and repair policies.

Modeling the water and wastewater flows, pressure heads, and quality in urban water conveyance, treatment, distribution, and collection systems is a challenging exercise, not only because of its hydraulic complexity, but also because of the stochastic inputs to and demands on the system. This chapter has attempted to provide an overview of some of the basic considerations used by modelers who develop computer-based optimization and simulation models for design and/or operation of parts of such systems. These same considerations should be in the minds of those who use such models as well. Much more detail can be found in many of the references listed at the end of this chapter.

\section{References}

Al-Zahrani, M. A., \& Moied, K. (2001). Locating water quality monitoring stations in water distribution systems. ASCE, Orlando, Florida: Proceedings of the World Water and Environmental Resources Congress.

Aral, M. M., Maslia, M. L., Ulirsch, G. V., \& Reyes, J. J. (1996). Estimating exposure to volatile organic compounds from municipal water supply systems: Use of a better computer model. Archives of Environmental Health, 51(4), 300-309.

Bedient, P. B., \& Huber, W. C. (1992). Hydrology and floodplain analysis, 2nd ed. Reading, MA: Addison-Westley Pub. Co.

Boulos, P. F., \& Wood, D. J. (1990). Explicit calculation of pipe-network parameters. Journal of Hydraulic Engineering, ASCE, 116(11), 1329-1344.

Chin, D. A. (2000). Water-resources engineering. Upper Saddle River, NJ: Prentice Hall. 
Dandy G., Kolokas, L., Frey, J., Gransbury, J., Duncker, A., \& Murphy, L. (2002). Optimal staging of capital works for large water distribution systems, In Proceedings, ASCE Environmental and Water Resources Planning Symposium, Roanoke, Va.

Dandy, G. C., \& Connarty, M. (1995). Use of genetic algorithms for project sequencing, integrated water resources planning for the 21 st century. In Proceedings of the 22nd Annual Conference, Water Resources Planning and Management Division (pp. 540-543). Cambridge, Mass: ASCE.

Dandy, G. C., \& Engelhardt, M. (2001). The optimal scheduling of water main replacement using genetic algorithms. Journal of Water Resources Planning and Management, ASCE, 127(4), 214-223.

Dandy, G. C., Simpson, A. R., \& Murphy, L. J. (1996). An improved genetic algorithm for pipe network optimization. Water Resources Research, 32(2), 449-458.

Datta, R. S. N., \& Sridharan, K. (1994). Parameter estimation in water-distribution systems by least squares. Journal of Water Resources Planning and Management, ASCE, 120(4), 405-422.

Department of Environmental Protection. (2012). NYC 2012 Green Infrastructure Annual Report. http://www. nyc.gov/html/dep/pdf/green_infrastructure/gi_annual_ report_2013.pdf

Greco, M., \& Del Guidice, G. (1999). New approach to water distribution network calibration. Journal of Hydraulic Engineering, ASCE, 125(8), 849-854.

Harding, B. L., \& Walski, T. M. (2002). Long time-series simulation of water quality in distribution systems. Proceedings, ASCE Environmental and Water Resources Planning Symposium, Roanoke, Va.

Huber, W. C., \& Dickinson, R. E. (1988). Storm water management model, Version 4, User's Manual. EPA/600/3-88/001a (NTIS PB88-236641/AS), U.S. EPA, Athens, GA, 30605. 595 pp. Also see http:// www.epa.gov/ednnrmrl/swmm/.

Lansey, K. E., \& Basnet, C. (1991). Parameter estimation for water distribution networks. Journal of Water Resources Planning and Management, ASCE, 117(1), 126-144.

Liggett, J. A., \& Chen, L. C. (1994). Inverse transient analysis in pipe networks. Journal of Hydraulic Engineering, ASCE, 120(8), 934-955.

Mays, L. W. (Ed.). (2000). Water distribution systems handbook. New York: McGraw-Hill.

Mays, L. W. (2001). Water resources engineering. New York: Wiley.

Murphy, L. J., Simpson, A. R., Dandy, G. C., Frey, J. P., \& Farrill, T. W. (1996). Genetic algorithm optimization of the Fort Collins-Loveland water distribution systems, Specialty Conference on Computers in the Water Industry (pp. 181-185). Chicago, Illinois: AWWA.

Ormsbee, L. E., \& Wood, D. J. (1986). Explicit pipe network calibration. Journal of Water Resources Planning and Management, 112(2), 166-182.
Price, R. K. (2002). Urban drainage modeling, course notes. Delft, NL: International Institute for Infrastructural, Hydraulic and Environmental Engineering.

Pudar, R. S., \& Liggett, J. A. (1992). Leaks in pipe networks. Journal of Hydraulic Engineering, ASCE, 118(7), 1031-1046.

Rahal, C. M., Sterling, M. J. H., \& Coulbeck, B. (1980). Parameter tuning for simulation models of water distribution networks. Proceedings of Institution of Civil Engineers, Part 2, 69, 751-762.

Reddy, P. V. N., Sridharan, K., \& Rao, P. V. (1996). WLS method for parameter estimation in water distribution networks. Journal of Water Resources Planning and management, ASCE, 122(3), 157-164.

Rodenbeck, S. E., \& Maslia, M. L. (1998). Groundwater modeling and GIS to determine exposure to TCE at Tucson. Practice Periodical of Hazardous, Toxic, and Radioactive Waste Management, ASCE, 2(2), 53-61.

Roesner, L. A., Aldrich, J. A., \& Dickinson, R. E. (1988). Storm Water Management Model User's Manual, Version 4: Addendum I, EXTRAN, EPA/600/3-88/001b (NTIS PB88236658/AS). Athens, GA: Environmental Protection Agency. 203 pp.

Savic, D. A., \& Walters, G. A. (1995). Genetic algorithm techniques for calibrating network models, Report No. 95/12, Centre for Systems and Control Engineering, University of Exeter, p. 41.

Savic, D. A., \& Walters, G. (1997). Genetic algorithms for least-cost design of water distribution networks. Journal of Water Resources Planning and Management, ASCE, 123(2), 67-77.

Savic, D. A., Walters, G. A., Randall Smith, M., \& Atkinson, R. M. (2000). Cost savings on large water distribution systems: Design through GA optimisation. Proceedings, Joint Conference on Water Resources Engineering and Water Resources Planning and Management, ASCE, Minneapolis, Minnesota.

Shamir, U. (1974). Optimal design and operation of water distribution systems. Water Resources Research, 10(1), 27-36.

Simpson, A. R., Dandy, G. C., \& Murphy, L. J. (1994). Genetic algorithms compared to other techniques for pipe optimization. Journal of Water Resources Planning and Management, ASCE, 120(4), 423-443.

Simpson, A. R., Sutton, D. C., Keane, D. S., \& Sheriff, S. J. (1999). Optimal control of pumping at a water filtration plant using genetic algorithms. In D. A. Savic \& G. A. Walters (Eds.), Water industry systems: Modelling and optimization applications (Vol. 2, pp. 407-415). Baldock, England: Research Studies Press Ltd.

Tucciarelli, T., Criminisi, A., \& Termini, D. (1999). Leak analysis in pipeline systems by means of optimal valve regulation. Journal of Hydraulic Engineering, ASCE, 125(3), 277-285.

Vitkovsky, J. P., \& Simpson, A. R. (1997). Calibration and leak detection in pipe networks using inverse transient analysis and genetic algorithms, Report No. $R$ 157, Department of Civil and Environmental Engineering, University of Adelaide, p. 97. 
Vitkovsky, J. P., Simpson, A. R., \& Lambert, M. F. (2000). Leak detection and calibration using transients and genetic algorithms. Journal of Water Resources Planning and Management, ASCE, 126(4), 262-265.

Walski, T. M. (1983). Technique for calibrating network models. Journal of Water Resources and Planning Management, ASCE, 109(4), 360-372.

Webler, T., \& Brown, I. S. (1993). Exposure to Tetrachloroethylene via contaminated drinking water pipes in Massachusetts: A predictive model. Archives of Environmental Health, 48(5), 293-297.

\section{Additional References (Further Reading)}

Alegre, H., \& Coelho, S. T. (2012). Infrastructure asset management of urban water systems, chapter 3. In A. Ostfeld (Ed.), Water supply system analysis - selected topics. doi:10.5772/52377, ISBN 978-953-51-0889-4

Axworthy, D. H., \& Karney, B. W. (1996). Modeling low velocity/high dispersion flow in water distribution systems. Journal of Water Resources Planning and Management, ASCE, 122(3), 218-221.

Bahri, A. (2012). Integrated urban water management, TEC background paper 16 global water partnership SE-111 51. Stockholm, Sweden: Printed by Elanders.

Chaudry, M.H., \& Islam, M. R. (1995). Water quality modeling in pipe networks. In E. Cabreran \& A. F. Vela (Eds.), Improving efficiency and reliability in water distribution systems. Dordrecht: Kluwer Academic Publishers.

Clark, R. M., Males, R., \& Stevie, R. G. (1984). Water supply simulation model volumes I, II and III., U.S. EPA, Cincinnati, OH.

Clark, R. M., Grayman, W. M., Males, R. M., \& Coyle, J. M. (1986). Predicting water quality in distribution systems", proceedings, distribution system symposium, AWWA, September 7-10 (pp. 155-180). Minnesota: Minneapolis.

EPA. (1992). CEAM Systems Development Life Cycle Methodology (SDLCM) Statement of Policy, Standards, and Guidelines-Version 1.00. U.S. EPA, Athens, GA, 30605.

Feyen, J., Shannon, K., \& Neville, M. (2008). Water and urban development paradigms: Towards an integration of engineering, design and management approaches. Boca Raton: CRC Press.

Grayman, W. M., Clark, R. M., \& Males, R. M. (1988). Modeling distribution system water quality: Dynamic approach. Journal of Water Resources Planning and Management, ASCE, 114(3), 295-312.

Grayman, W. M., Loucks, D. P., \& Saito, L. (Eds.). (2012). Toward a sustainable water future: Visions for 2050. Reston, VA: ASCE Press.

Hering, J. G., Waite, T. D., Luthy, R. G., Drewes, J. E., \& Sedlak, D. L. (2013). A changing framework for urban water systems environment. Science Technology, 47, 10721-10726. dx.doi.org/10.1021/es4007096

Hutton, C. J., Vamvakeridou-Lyroudia, L. S., Kapelan, Z., \& Savic, D. A. (UNEXE). (2011). Uncertainty quantification and reduction in urban water systems (UWS) modelling: Evaluation Report D3.6.1 prepared 2011.005, A framework for integrated modeling of urban systems.

Islam, M. R., \& Chaudry, M. H. (1998). Modeling of constituent transport in unsteady flows in pipe networks. Journal of Hydraulic Engineering, ASCE, 124(11), 1115-1124.

Medows, M. E., Walski, T. M., et al. (Eds.). (1997). Computer applications in hydraulic engineering. Waterbury, CT: Haestad Press, Haestad Methods Inc.

Morley, M. S., Atkinson, R. M., Savic, D. A., \& Walters, G. A. (2001). GAnet: Genetic algorithm platform for pipe network optimisation. Advances in Engineering Software, 32(6), 467-475.

Grimm, N. B., Grove, J. M., Pickett, S. T. A., \& Redman, C. L. (2000). Integrated approaches to long-term studies of urban ecological systems. BioScience, 50 (7), 571-584.

Ormsbee, L. E. (1989). Implicit network calibration. Journal of Water Resources Planning and Management, ASCE, 115(2), 243-257.

Ostfeld, A. (ed). (2012). Water supply system analysisselected topics, ISBN 978-953-51-0889-4, 158 pages, Publisher: InTech, doi:10.5772/2882

Pickett, S. T. A., Cadenasso, M. L., Grove, J. M., Nilon, C. H., Pouyat, R. V., Zipperer, W. C., \& Costanza, R. (2001). Linking terrestrial ecological, physical, and socioeconomic components of metropolitan areas, urban ecological systems. Annual Review of Ecology System, 32, 127-57.

Rossman, L. A., Boulos, P. F., \& Altman, T. (1993). Discrete volume-element method for network water quality models. Journal of Water Resources Planning and Management, ASCE, 119(5), 505-517.

Rossman, L. A., Clark, R. M., \& Grayman, W. M. (1994). Modeling chlorine residuals in drinking-water distribution systems. Journal of Environmental Engineering, ASCE, 120(4), 803-820.

Shamir, U., \& Howard, C. D. D. (1968). Water distribution systems analysis. Journal of the Hydraulic Division, ASCE, 94(1), 219-234.

Tang, K., Karney, B., Pendlebury, M., \& Zhang, F. (1999). Inverse transient calibration of water distribution systems using genetic algorithms. In D. A. Savic \& G. A. Walters (Eds.), Proceedings of Water Industry Systems: Modelling and Optimisation Applications (Vol. 1, pp. 317-326). Exeter, UK.

Todini, E. (1999). Using a Kalman Filter approach for looped water distribution network calibration. In D. A. Savic \& G. A. Walters (Eds.), Proceedings of Water Industry Systems: Modelling and Optimisation Applications (Vol. 1, pp. 327-336), Exeter, UK.

United Nations World Water Development Report No. 4. (2012). World Water Assessment Programme. Paris: UNESCO. 
Viessman, W. Jr., \& Welty, C. (1985). Water Management Technology and Institutions. New York: Harper \& Row, Pub.

\section{Exercises}

12.1 Define the components of the infrastructure needed to bring water into your home and then collect the wastewater and treat it prior to discharging it back into a receiving water body. Draw a schematic of such a system and show how it can be modeled to determine the best design variable values. Define the data needed to model such a system and then make up values of the needed parameters and solve the model of the system.

12.2 Compare the curve number approach to the use of Manning's equation to estimate urban runoff quantities. Then define how you would predict quality and sediment runoff as well.

12.3 Develop a simple model for predicting the runoff of water, sediment, and several chemicals from a 10-ha urban watershed in the northeastern United States during August 1976. Recorded precipitation was as follows:

\begin{tabular}{l|l|l|l|l|l|l|l|l|l|l|l}
\hline Day & 1 & 6 & 7 & 8 & 9 & 10 & 13 & 14 & 15 & 26 & 29 \\
\hline$R_{1}(\mathrm{~cm})$ & 1.8 & 0.7 & 2.6 & 2.9 & 0.1 & 0.3 & 2.9 & 0.1 & 1.4 & 3.7 & 0.8 \\
\hline
\end{tabular}

Solids (sediment) buildup on the watershed at the rate of $50 \mathrm{~kg} / \mathrm{ha}$-day, and chemical concentrations in the solids are $100 \mathrm{mg} / \mathrm{kg}$. Assume that each runoff event washes the watershed surface clean. Assume also that there is no initial sediment buildup on August. The watershed is $30 \%$ impervious. For each storm use your model to compute:

(a) Runoff in $\mathrm{cm}$ and $\mathrm{m}^{3}$.

(b) Sediment loss $(\mathrm{kg})$.

(c) Chemical loss (g), in dissolved and solid-phase form for chemicals with three different adsorption coefficients, $k=5$, $100,1000$.
12.4 There exists a modest-sized urban subdivision of 100 ha containing 2000 people. Land uses are $60 \%$ single-family residential, $10 \%$ commercial, and $30 \%$ undeveloped. An evaluation of the effects of street-cleaning practices on nutrient losses in runoff is required for this catchment.

This evaluation is to be based on the 7-month precipitation record given below. Present the results of the simulations as 7-month $\mathrm{PO}_{4}$ and $\mathrm{N}$ losses as functions of street-cleaning interval and efficiency (i.e., show these losses for ranges of intervals and efficiencies). Assume a runoff threshold for washoff of $Q_{\mathrm{o}}=0.5 \mathrm{~cm}$.

\begin{tabular}{|c|c|c|c|c|c|c|c|}
\hline \multicolumn{8}{|c|}{ Precipitation $(\mathrm{cm})$} \\
\hline Day & A & M & $\mathrm{J}$ & $\mathrm{J}$ & A & $\mathrm{S}$ & $\mathrm{O}$ \\
\hline 1 & & & 0.6 & & 1.4 & 0.7 & 1.9 \\
\hline 2 & 1.1 & 0.4 & & & & 0.5 & \\
\hline 3 & & & & & & 0.1 & 0.1 \\
\hline 4 & 0.1 & 1.5 & & & & & \\
\hline 5 & 0.1 & 0.9 & & \multirow[t]{2}{*}{1.4} & 1.9 & 0.3 & \\
\hline 6 & 0.1 & & 1.4 & & 1.0 & & 0.5 \\
\hline 7 & & & 0.1 & 1.1 & 0.7 & & \\
\hline $\mathrm{S}$ & 0.1 & 0.1 & & 0.7 & & & 0.4 \\
\hline 9 & & 0.6 & 1.6 & 0.1 & & & 1.5 \\
\hline 10 & & & & & 0.1 & & \\
\hline \multicolumn{8}{|l|}{11} \\
\hline 12 & & & & 02 & 02 & & 02 \\
\hline 13 & 0.1 & & & 0.2 & & 1.5 & \\
\hline 14 & & & 02 & & 0.5 & 3.5 & 0.8 \\
\hline 15 & & & & & & & 1.0 \\
\hline 16 & & & & & & 4.3 & 2.8 \\
\hline 17 & & & 0.7 & 0.8 & 0.5 & 0.8 & 1.9 \\
\hline 18 & & 0.5 & 0.4 & 0.1 & & 0.8 & 0.1 \\
\hline 19 & & & 0.4 & & & 0.4 & 0.9 \\
\hline 20 & & & 0.7 & 03 & & 2.3 & \\
\hline 21 & & & & & & 0.3 & \\
\hline 22 & 0.1 & & & 0.1 & 0.4 & & \\
\hline 23 & 2.0 & & & & & & \\
\hline 24 & 3.2 & 0.1 & & & 02 & 4.7 & \\
\hline 25 & 0.1 & & 0.6 & & & 2.8 & \\
\hline
\end{tabular}




\begin{tabular}{l|l|l|l|l|l|l|l}
\hline \multicolumn{2}{l}{ Precipitation (cm) } & \multicolumn{1}{l}{} \\
\hline 26 & & & & 3.0 & & 1.6 & \\
\hline 27 & & & & & & & \\
\hline 28 & & & 0.3 & & & 0.1 & \\
\hline 29 & 02 & 1.1 & & & & \\
\hline 30 & 0.1 & & & 0.6 & & \\
\hline 31 & & & & & 0.2 & & \\
\hline
\end{tabular}

12.5 Managing the quantity and quality of stormwater runoff is a common urban problem. Discuss the factors to be considered when planning storm sewer networks and detention basins, and how might simulation and/or optimization methods be used to help do this.

12.6 Multiple connected pipeline networks are commonly make up urban water distribution systems. Define a simple pipeline network and develop an optimization model for finding the flows and heads in the network needed to provide required flow discharges and pressures at various nodes or junctions of the network. Discuss some of the complicating issues associated with the design of such networks that your model may not be considering.

12.7 Consider a wastewater treatment plant and associated effluent detention pond designed to release treated and stored effluent into a stream so as to adapt to varying effluent concentration standards associated with varying stream assimilative capacities as its flow and water temperature and existing pollutant loads vary over time. Develop a model for estimating the treatment plant efficiency for BOD removal, and the size of the detention basin, needed to meet the varying effluent standards of the receiving stream, at a minimum cost. Define the data you will need to do this, and all model parameters. Why might this proposed adaptive treatment scheme not be very practical?

12.8 Urban Infrastructural Asset Management is increasingly becoming a key topic in the move toward increased sustainability of water supply and wastewater systems. List some characteristics of sustainable infrastructural systems.
Open Access This chapter is distributed under the terms of the Creative Commons Attribution-NonCommercial 4.0 International License (http://creativecommons.org/ licenses/by-nc/4.0/), which permits any noncommercial use, duplication, adaptation, distribution and reproduction in any medium or format, as long as you give appropriate credit to the original author(s) and the source, provide a link to the Creative Commons license and indicate if changes were made.
The images or other third party material in this chapter are included in the work's Creative Commons license, unless indicated otherwise in the credit line; if such material is not included in the work's Creative Commons license and the respective action is not permitted by statutory regulation, users will need to obtain permission from the license holder to duplicate, adapt or reproduce the material. 